$15^{\text {th }}$ International Conference on

AEROSPACE SCIENCES \& AVIATION TECHNOLOGY,

$\boldsymbol{A S A T}$ - 15 - May 28 - 30, 2013, Email: asat@mtc.edu.eg,

Military Technical College, Kobry Elkobbah, Cairo, Egypt,

Tel: +(202) 24025292 -24036138, Fax: +(202) 22621908

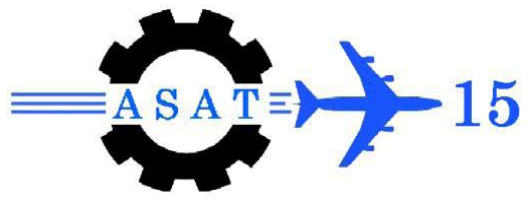

\title{
Modeling and Analysis of Laminated Composite Plate Using Modified Higher Order Shear Deformation Theory
}

\author{
M. K. Abbas ${ }^{*}$, M. A. Elshafei ${ }^{\dagger}$, H. M. Negm ${ }^{\ddagger}$
}

\begin{abstract}
In the present work, a modified higher-order shear deformation theory is developed to analyze isotropic and composite plates to obtain the static response as well as dynamic characteristics using Ritz solution technique. The displacement-field equations of Lo's higher order shear deformation theory are modified by representing the total rotation of the normal to the mid-plane by two components, bending and shear rotations. The model is valid for thin and thick plates. The plates are subjected to mechanical loads with different types of boundary conditions. A Mathematica code is developed to analyze different plate problems. The obtained results are compared to the available studies solved by different theories and finite element methods. It is shown that the obtained results are accurate using less number of degrees of freedom.
\end{abstract}

Keywords: Higher-order shear deformation theory, Ritz energy method, composite material mechanics, static and dynamic analysis

\section{Introduction}

A considerable amount of work are published concerning the analysis of isotropic and composite plates using different theories based on the classical plate theory (CPT), first order shear deformation theory (FSDT), and higher order deformation theories(HSDT).

Reissner [1], provided a consistent theory which incorporates the effect of shear deformation, called first order shear deformation theory (FSDT). Displacement field equations of (FSDT) allow a uniform shear stress through the thickness, which violates surface conditions. Mindlin [2], introduced a shear correction factor into the shear stress resultants, where the shear stress vanishes at the stress-free surfaces. The correction factor was evaluated by comparison with an exact three-dimensional elasticity solution, [3]. Giles, [4], presented the kinematic plate assumptions of the modified first-order shear deformation theory (MFSDT), [5] to improve his prediction.

Hildebrand et. al [6], briefly examined a second order theory. They concluded that the inclusion of the quadratic terms in the in-plane displacements does not provide a significant advantage over the lower level theory, for problems of interest.

Reddy, [7], simplified the cubic displacement field equations for conventional composite laminates using stress-free boundary conditions, with no need for the shear correction factor, while Lo's Higher order theory of plate deformation, [8, 9], avoided this restriction. Displacement field equations include the effect of transverse normal strain, which makes it suitable for thick plates. The advantages of the Lo's Higher order theory of plate deformation are; (i) It is suitable for both thick and thin composite structures. (ii) There is no need for a shear correction factor. (iii) Transverse shear effects can be modeled as a parabolic transverse

\footnotetext{
*Egyptian Armed Forces, Egypt.

Egyptian Armed Forces, Egypt; maelshafei@yahoo.com .

*Department of Aerospace Engineering, Cairo University, Cairo, Egypt.
} 
shear strain across the thickness of the structure. (iv) Transverse normal strain is also included in the model. (v) Little restriction exists on the type of problem because the displacement field is independent of boundary conditions and material properties, [10,11].

Pagano et al. [12], introduced an exact solution for square bidirectional laminates under sinusoidal loading using the theory of elasticity. He concluded that a conservative estimate of the magnitude of the error reflected in the simplifying assumption of CPT for multilayered systems can be achieved by comparison of exact and approximate solutions for laminates consisting of only several layers.

Noor [13] used the three-dimensional theory of elasticity to discuss the validity of twodimensional plate theories when applied to the low frequency free vibration analysis of simply supported, bidirectional, multilayered plates. He concluded that for composite plates the error in the predictions of the CPT is strongly dependent on the number and stacking of the layers, in addition to the degree of orthotropy of the individual layers and the thickness ratio of the plate.

Kwon et al. [14], introduced high- order displacement field equations for the analysis of layered composite plates. A parabolic distribution of the transverse shear strain was considered in the equations, and a mixed finite element model was developed from the proposed equations. They found that their model gives reasonable results for thin and thick plates compared with three- dimensional elasticity solution of Pagano et al. [12].

Yuan et al. [15], introduced a straightforward displacement type rectangular finite element for bending of a flat plate with the inclusion of transverse shear effects. The results showed that their element was more flexible than most other moderately thick plate finite elements and agree closely with those from a numerical solution of the three dimensional elasticity equations.

Zeng et al. [16], used a new higher order theory to model laminated plates and shells. They studied symmetric, anti-symmetric and cross-ply laminated plates, and cylindrical and spherical shells. They used higher order displacement field of order 4 in the transverse coordinate $(\mathrm{z})$ to present the in-plane displacements $(\mathrm{u}, \mathrm{v})$. Their model improved the in-plane stress distribution without complicating the problem.

Ghosh, et al. [17, 18] developed a four-noded rectangular element with seven degrees of freedom at each node for the analysis of laminated plates. Their element confirmed its applicability for a wide variety of laminated composite plates. They recommended that for higher aspect ratios one may use their element but for lower aspect ratios, Phan and Reddy's element [19] has better accuracy. For vibration analysis of laminated composite plate structures having a constant thickness of any individual layer, they concluded that for simply supported laminated plates, increasing lamination angle $\theta$ (up to $45^{\circ}$ ) increases the fundamental frequency, except for the case of two-layer plate. Increasing the number of layers without changing the total thickness increases the fundamental frequency. The effect of plate aspect ratio on the fundamental frequency is more pronounced in thicker plates than the case of thin plates.

Roy, et al. [20], investigated the effects of variations in the thickness profile on the displacements and dynamic bending stresses of a square cantilever plate excited by a point harmonic load. A four-noded plate element was used for the analysis. The response was determined for the first three modes of vibration. In each case the results obtained for different thickness profiles were compared with those of the uniform thickness plate. It was observed that considerable reductions in displacement amplitudes and bending stresses can be achieved by the proper selection of thickness profile.

Xiaoping Shu et al. [21], developed an improved simple higher-order shear deformation theory for laminated composite plates. The theory contains the same number of dependent variables as in the FSDT, and accounts for parabolic distribution of transverse shear strain through the thickness of the plate and transverse shear stress continuity across each layer 
interface. Although their theory contains five dependent variables, it gives more accurate results than some higher-order theories.

Kabir [22], presented an analytical solution to a moderately thick simply supported rectangular plate with symmetric angle-ply lamination. The Resissner-Mindlin theory that incorporates transverse shear deformation into plate formulation characterizing the moderately thick behavior was considered. The plate deformation behavior in bending was defined by three highly coupled second-order partial differential equations in three unknowns. Theses equations, in conjunction with the admissible boundary conditions, were solved using a displacement-based double Fourier series approach. The solution agreed with the published finite element results for both moderately thick and thin plates.

Akhras et al. [23], developed a finite strip method for the analysis of anisotropic laminated composite plates based on a HSDT. The used method improved the results compared with FSDT while using approximately the same number of degrees of freedom. It also eliminates the need for shear correction factors in calculating the transverse shear stiffness.

Qatu et al. [24], introduced a consistent set of equations for modeling laminated plates and shallow shells. Exact solutions which satisfy the equations of equilibrium and boundary conditions were obtained for shear diaphragm boundaries and cross-ply laminates. The Ritz method is used to obtain the deflections and stresses for generally laminated plates and shallow shells with cantilevered and doubly-cantilevered boundaries. Isotropic and laminated composites are considered for both plates and cylindrical shell panels. They concluded that it was necessary to provide more than 140 degrees of freedom in terms of displacement polynomials using Ritz method in order to obtain reasonably accurate results, especially for the stress and moment resultants.

Verijenko et al [25], introduced a finite element formulation for the analysis of laminated composite plates based on a higher order theory. Different types of finite elements which take into account transverse shear and normal deformation are developed. The proposed finite element is highly efficient and accurate, and can be used easily be incorporating them into existing finite element codes.

Kong et al. [26] proposed a displacement based three dimensional finite element scheme for the analysis of thick laminated plates. The thick laminated plate was treated as a threedimensional inhomogeneous anisotropic elastic body. Layerwise, local shape functions were used in the regions where transverse shear stress was of interest, while an ad hoc global-local interpolation was used in the region where only the general deformation pattern is concerned. For satisfying the displacement compatibility between these two regions, a transition zone was introduced. The model incorporates the advantages of the layerwise theory and the single-layer theory.

Li et al. [27], used Reddy's theory, with the effect of higher order shear deformations, to derive the governing equations of bending of orthotropic plates with finite deformations. Numerical results showed that the influence of the shear deformation on the static bending of orthotropic moderately thick plate is significant.

Manna [28], used a high order triangular element to investigate free vibration of isotropic rectangular plates with different thickness ratios, boundary conditions, and aspect ratios. The FSDT is used to include the effect of transverse shear deformation. The element has 51 degrees of freedom. Rotary inertia has been included in the consistent mass matrix. His results showed the accuracy and convergence characteristics of the element.

The present work presents a Modified Higher Order Shear Deformation Theory, in which the displacement-field equations of Lo's higher order shear deformation theory are modified by representing the total rotation of the normal to the mid-plane by two components, bending and shear rotations to refine the obtained results. It converges to the exact solution using Ritz approximation technique with less number of degrees of freedom, and less computational time. The model is suitable for thin and thick laminated composite plates. 


\section{Displacement Field Equations}

The displacement field equations for different theories can be written as

$$
\begin{gathered}
u(x, y, z, t)=u_{0}+z\left(C_{1} \frac{\partial w_{0}}{\partial x}+C_{2} \theta_{x}\right)+C_{3} z^{2} \psi_{x}+z^{3}\left[C_{4} \xi_{x}+C_{5} \frac{4}{3 h^{2}}\left(\theta_{x}+\frac{\partial w_{0}}{\partial x}\right)\right] \\
v(x, y, z, t)=v_{0}+z\left(C_{1} \frac{\partial w_{0}}{\partial y}+C_{2} \theta_{y}\right)+C_{3} z^{2} \psi_{y}+z^{3}\left[C_{4} \xi_{y}+C_{5} \frac{4}{3 h^{2}}\left(\theta_{y}+\frac{\partial w_{0}}{\partial y}\right)\right] \\
w(x, y, z, t)=w_{0}+C_{6} z \theta_{z}+C_{7} z^{2} \psi_{z}
\end{gathered}
$$

where $u_{0}, v_{0}$, and $w_{0}$ are displacements at the mid-plane in the $\mathrm{x}, \mathrm{y}$, and $\mathrm{z}$ directions respectively. $\theta_{x}$, and $\theta_{y}$, are the rotations of the normal to the mid-plane about the y-axis, and $\mathrm{x}$-axis, respectively. They are defined in MFSDT and MHSDT as the shear rotation angles. $\theta_{z}$ is a first order displacement representing the extension in the plain normal to the mid-plane. $\psi_{x}, \psi_{y}$, and $\psi_{z}$ are second order displacements or warping functions. $\xi_{x}$, and $\xi_{y}$ are third order displacements or warping functions, where all the previous symbols are function of $(x, y, t) . h$ is the total laminate thickness. $C_{1}, C_{2}, C_{3}, C_{4}, C_{5}, C_{6}$ and $C_{7}$ are constants associated with the used deformation theory.

Table 1 gives the values of the constants for various theories illustrated in Fig. 1.

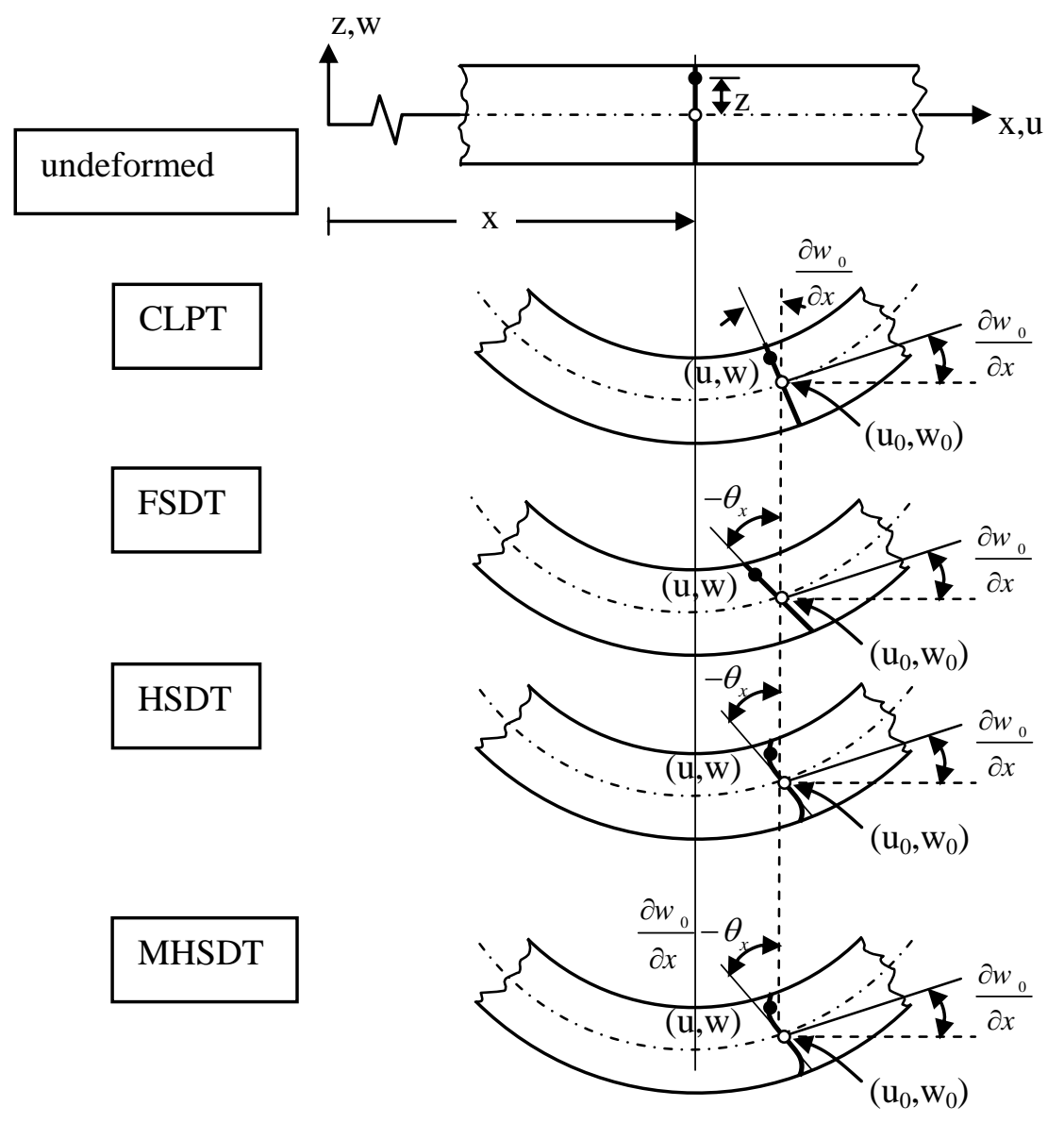

Fig. 1. Deformation of a transverse normal according to the classical, first order, and higher order and modified higher order shear deformation theories 
Table 1. The values of the constants for different shear deformation theories

\begin{tabular}{|c|c|c|c|c|c|c|c|}
\hline Theory & $C_{1}$ & $C_{2}$ & $C_{3}$ & $C_{4}$ & $C_{5}$ & $C_{6}$ & $C_{7}$ \\
\hline Kirchoff”s Classical Lamination The“ory (CLT), [7] & -1 & 0 & 0 & 0 & 0 & 0 & 0 \\
\hline $\begin{array}{l}\text { Mindlin's First Order Shear Deformation Theory } \\
\text { (FSDT), }[7,8]\end{array}$ & 0 & 1 & 0 & 0 & 0 & 0 & 0 \\
\hline $\begin{array}{l}\text { Modified First Order Shear Deformation Theory } \\
(\text { MFSDT), }[4,5]\end{array}$ & -1 & 1 & 0 & 0 & 0 & 0 & 0 \\
\hline Second Order Plate Theory (SPT), [29] & 0 & 1 & 1 & 0 & 0 & 0 & 0 \\
\hline Reddy’s (HSDT), [7] & 0 & 1 & 0 & 0 & -1 & 0 & 0 \\
\hline Lo's Higher Order Plate Theory (LoHPT), $[8,9]$ & 0 & 1 & 1 & 1 & 0 & 1 & 1 \\
\hline $\begin{array}{l}\text { Modified Higher Order Shear Deformation Theory } \\
\text { (MHSDT) (Present Model) }\end{array}$ & -1 & 1 & 1 & 1 & 0 & 1 & 1 \\
\hline
\end{tabular}

The Modified Higher Order Shear Deformation Theory (MHSDT) displacement field equations are represented as follows:

$$
\begin{gathered}
u(x, y, z, t)=u_{0}(x, y, t)+z\left(\theta_{x}(x, y, t)-\frac{\partial w_{0}(x, y, t)}{\partial x}\right)+z^{2} \psi_{x}(x, y, t)+z^{3} \xi_{x}(x, y, t) \\
v(x, y, z, t)=v_{0}(x, y, t)+z\left(\theta_{y}(x, y, t)-\frac{\partial w_{0}(x, y, t)}{\partial y}\right)+z^{2} \psi_{y}(x, y, t)+z^{3} \xi_{y}(x, y, t) \\
w(x, y, z, t)=w_{0}(x, y, t)+z \theta_{z}(x, y, t)+z^{2} \psi_{z}(x, y, t)
\end{gathered}
$$

\section{Strain-Displacement Relationships}

The strain-displacement relationships can be expressed in a matrix form as follows:

$$
\{\varepsilon\}=\left\{\varepsilon^{0}\right\}+z\left\{\varepsilon^{1}\right\}+z^{2}\left\{\varepsilon^{2}\right\}+z^{3}\left\{\varepsilon^{3}\right\}
$$

where

$$
\{\varepsilon\}^{T}=\left[\begin{array}{llllll}
\varepsilon_{x x} & \varepsilon_{y y} & \varepsilon_{z z} & \gamma_{y z} & \gamma_{z x} & \gamma_{x y}
\end{array}\right]
$$

$\left\{\varepsilon^{0}\right\}^{T}=\left[\begin{array}{llllll}\frac{\partial u_{0}}{\partial x} & \frac{\partial v_{0}}{\partial y} & \theta_{z} & \theta_{y} & \theta_{x} & \frac{\partial u_{0}}{\partial y}+\frac{\partial v_{0}}{\partial x}\end{array}\right] \oplus$

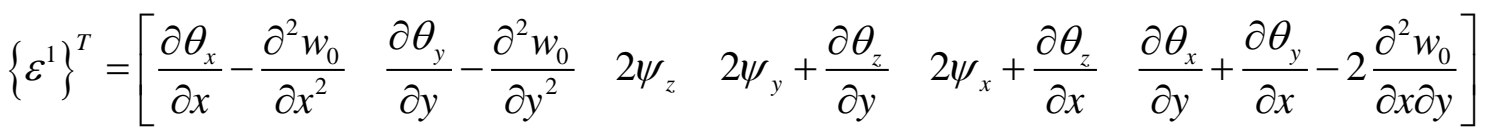

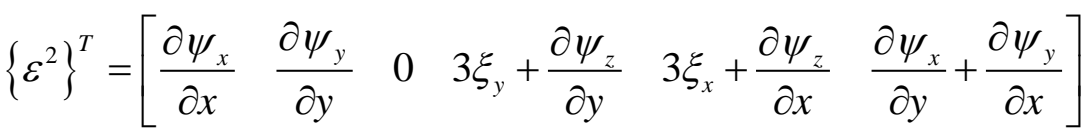

$\left\{\varepsilon^{3}\right\}^{T}=\left[\begin{array}{llllll}\frac{\partial \xi_{x}}{\partial x} & \frac{\partial \xi_{y}}{\partial y} & 0 & 0 & 0 & \frac{\partial \xi_{x}}{\partial y}+\frac{\partial \xi_{y}}{\partial x}\end{array}\right]$ 


\section{Stress-Strain Relationships}

The generalized stress-strain relations can be written in contracted notation as follows, [7, 30]:

$$
\sigma_{i}=Q_{i j} \varepsilon_{j} \quad i, j=1,2, \ldots 6
$$

The transformed stress-strain relations for an orthotropic lamina oriented by an angle $\theta$ can be written as:

$$
\left\{\begin{array}{l}
\sigma_{x} \\
\sigma_{y} \\
\sigma_{z} \\
\tau_{y z} \\
\tau_{z x} \\
\tau_{x y}
\end{array}\right\}=\left[\begin{array}{llllll}
\overline{Q_{11}} & \bar{Q}_{12} & \bar{Q}_{13} & 0 & 0 & \bar{Q}_{16} \\
\overline{Q_{21}} & \bar{Q}_{22} & \bar{Q}_{23} & 0 & 0 & \bar{Q}_{26} \\
\overline{Q_{31}} & \bar{Q}_{32} & \bar{Q}_{33} & 0 & 0 & \bar{Q}_{36} \\
0 & 0 & 0 & \bar{Q}_{44} & \bar{Q}_{45} & 0 \\
0 & 0 & 0 & \bar{Q}_{54} & \overline{Q_{55}} & 0 \\
\overline{Q_{61}} & \bar{Q}_{62} & \overline{Q_{63}} & 0 & 0 & \bar{Q}_{66}
\end{array}\right]\left\{\begin{array}{l}
\varepsilon_{x} \\
\varepsilon_{y} \\
\varepsilon_{z} \\
\gamma_{y z} \\
\gamma_{z x} \\
\gamma_{x y}
\end{array}\right\}
$$

The elements of the transformed symmetric stiffness matrix $[\bar{Q}]$, is listed in Appendix (A), $[7,30]$.

\section{Energy Formulation}

The Hamilton's principle is used to obtain the governing equations of motion, [7] :

$$
0=\int_{0}^{T}(\delta U+\delta V-\delta K) d t
$$

The virtual strain energy, $\delta U$, is given by, [7]:

$$
\delta U=\int_{V}\left(\{\delta \varepsilon\}^{T}\{\sigma\}\right) d V
$$

Thus

$$
\delta U=\int_{A}\left\{\sum_{i=1}^{k} \int_{z_{i-1}}^{z_{i}} \delta\{\varepsilon\}^{T}[\bar{Q}]_{i}\{\varepsilon\} d z\right\} d x d y
$$

where $\mathrm{Z}_{\mathrm{i}-1}, \mathrm{z}_{\mathrm{i}}$ are the lower and upper $\mathrm{z}$ - coordinates of layer number $(i)$ measured from mid-plane, respectively. $k$ is the total number of layers in the laminate. Substituting for the strain from Eq.(3):

$$
\left.\delta U=\int_{A}\left\{\sum_{i=1}^{k} \int_{z_{i-1}}^{z_{i}}\left(\delta\left\{\varepsilon^{0}\right\}^{T}+z \delta\left\{\varepsilon^{0}\right\}^{T}+z\left\{\varepsilon^{1}\right\}+z^{2}\left\{\varepsilon^{2}\right\}+z^{3}\left\{\varepsilon^{2}\right\}^{T}+z^{3} \delta\left\{\varepsilon^{3}\right\}^{T}\right)[\bar{Q}]_{i}\right]\right\} d x d y
$$

The virtual strain energy $\delta U$ can be rewritten as follows

$$
\delta U=\int_{A}\left\{\begin{array}{l}
\delta\left\{\varepsilon^{0}\right\}^{T}[A]\left\{\varepsilon^{0}\right\}+\delta\left\{\varepsilon^{0}\right\}^{T}[B]\left\{\varepsilon^{1}\right\}+\delta\left\{\varepsilon^{0}\right\}^{T}[D]\left\{\varepsilon^{2}\right\}+\delta\left\{\varepsilon^{0}\right\}^{T}[E]\left\{\varepsilon^{3}\right\} \\
+\delta\left\{\varepsilon^{2}\right\}^{T}[D]\left\{\varepsilon^{0}\right\}+\delta\left\{\varepsilon^{2}\right\}^{T}[E]\left\{\varepsilon^{1}\right\}+\delta\left\{\varepsilon^{2}\right\}^{T}[F]\left\{\varepsilon^{2}\right\}+\delta\left\{\varepsilon^{2}\right\}^{T}[H]\left\{\varepsilon^{3}\right\} \\
+\delta\left\{\varepsilon^{3}\right\}^{T}[E]\left\{\varepsilon^{0}\right\}+\delta\left\{\varepsilon^{3}\right\}^{T}[F]\left\{\varepsilon^{1}\right\}+\delta\left\{\varepsilon^{3}\right\}^{T}[H]\left\{\varepsilon^{2}\right\}+\delta\left\{\varepsilon^{3}\right\}^{T}[J]\left\{\varepsilon^{3}\right\}
\end{array}\right\}
$$

where A, B, D are the extensional, coupling, and bending stiffness matrices. The matrices E, $\mathrm{F}, \mathrm{H}, \mathrm{J}$ are the higher order stiffness matrices, and given as: 


$$
(A, B, D, E, F, H, J)=\sum_{i=1}^{k} \int_{z_{i-1}}^{z_{i}} \overline{Q_{i}}\left(1, z, z^{2}, z^{3}, z^{4}, z^{5}, z^{6}\right) d z
$$

The virtual work $\delta V$ done by the applied forces can be written as, [5]

$$
\delta V=\int_{A}\left\{p_{z}(x, y) \delta w(x, y, 0, t)\right\} d x d y+F_{z i} \delta w\left(x_{i}, y_{i}, 0, t\right)
$$

where $p_{z}(x, y)$ is the transverse distributed load, and $\mathrm{F}_{\mathrm{zi}}$ is the concentrated force in the $\mathrm{z}$ direction at point (i).

The virtual kinetic energy, $\delta K$, can be written as, [7]

$$
\delta K=\int_{V} \rho\left[\delta\{\dot{U}\}^{T}\{\dot{U}\}\right] d V
$$

where

$$
\{U\}^{T}=\left[\begin{array}{lll}
u & v & w
\end{array}\right]
$$

For k layers Eq.(15) is represented as

$$
\delta K=\int_{A}\left\{\sum_{i=1}^{k} \int_{z_{i-1}}^{z_{i}} \rho_{i}\left[\delta\{\dot{U}\}^{T}\{\dot{U}\}\right] d z\right\} d x d y
$$

where $\rho_{i}$ is the density of layer number $(i)$.

Substituting the displacement field Eq.(2), we can write

$$
\{U\}=\left\{U^{0}\right\}+z\left\{U^{1}\right\}+z^{2}\left\{U^{2}\right\}+z^{3}\left\{U^{3}\right\}
$$

where

$$
\begin{aligned}
& \left\{U^{0}\right\}^{T}=\left[\begin{array}{lll}
u_{0} & v_{0} & w_{0}
\end{array}\right],\left\{U^{1}\right\}^{T}=\left[\begin{array}{lll}
\theta_{x}-\frac{\partial w_{0}}{\partial x} & \theta_{y}-\frac{\partial w_{0}}{\partial y} & \theta_{z}
\end{array}\right], \\
& \left\{U^{2}\right\}^{T}=\left[\begin{array}{lll}
\psi_{x} & \psi_{y} & \psi_{z}
\end{array}\right],\left\{U^{3}\right\}^{T}=\left[\begin{array}{lll}
\xi_{x} & \xi_{y} & 0
\end{array}\right]
\end{aligned}
$$

Substituting Eq.(18) into Eq.(17), we can write;

$$
\delta K=\int_{A}\left(\begin{array}{l}
I_{0} \delta\left\{\dot{U}^{0}\right\}^{T}\left\{\dot{U}^{0}\right\}+I_{1} \delta\left\{\dot{U}^{0}\right\}^{T}\left\{\dot{U}^{1}\right\}+I_{2} \delta\left\{\dot{U}^{0}\right\}^{T}\left\{\dot{U}^{2}\right\}+I_{3} \delta\left\{\dot{U}^{0}\right\}^{T}\left\{\dot{U}^{3}\right\} \\
+I_{1} \delta\left\{\dot{U}^{1}\right\}^{T}\left\{\dot{U}^{0}\right\}+I_{2} \delta\left\{\dot{U}^{1}\right\}^{T}\left\{\dot{U}^{1}\right\}+I_{3} \delta\left\{\dot{U}^{1}\right\}^{T}\left\{\dot{U}^{2}\right\}+I_{4} \delta\left\{\dot{U}^{1}\right\}^{T}\left\{\dot{U}^{3}\right\} \\
+I_{2} \delta\left\{\dot{U}^{2}\right\}^{T}\left\{\dot{U}^{0}\right\}+I_{3} \delta\left\{\dot{U}^{2}\right\}^{T}\left\{\dot{U}^{1}\right\}+I_{4} \delta\left\{\dot{U}^{2}\right\}^{T}\left\{\dot{U}^{2}\right\}+I_{5} \delta\left\{\dot{U}^{2}\right\}^{T}\left\{\dot{U}^{3}\right\} \\
+I_{3} \delta\left\{\dot{U}^{3}\right\}^{T}\left\{\dot{U}^{0}\right\}+I_{4} \delta\left\{\dot{U}^{3}\right\}^{T}\left\{\dot{U}^{1}\right\}+I_{5} \delta\left\{\dot{U}^{3}\right\}^{T}\left\{\dot{U}^{2}\right\}+I_{6} \delta\left\{\dot{U}^{3}\right\}^{T}\left\{\dot{U}^{3}\right\}
\end{array}\right) d x d y
$$

where

$$
\left(I_{0}, I_{1}, I_{2}, I_{3}, I_{4}, I_{5}, I_{6}\right)=\sum_{i=1}^{k} \int_{z_{i-1}}^{z_{i}} \rho_{i}\left(1, z, z^{2}, z^{3}, z^{4}, z^{5}, z^{6}\right) d z
$$

Substituting Eq.(12), Eq.(14), and Eq.(20) into Eq.(8), the equations of motion can be obtained.

\section{Ritz Solution Technique}

In the Ritz method the unknown displacements $u_{0}, v_{0}, w_{0}, \theta_{x}, \theta_{y}, \theta_{z}, \psi_{x}, \psi_{y}, \psi_{z} \xi_{x}, \xi_{y}$ of the given problem are approximated by $x$-y-dependent functions that satisfy the geometric boundary conditions as follows 


$$
\gamma_{i}(x, y, t)=\left\{a_{i}(x, y)\right\}^{T}\left\{q_{i}(t)\right\} \quad i=1,2 \ldots 11
$$

where $\gamma_{i}(x, y, t)$ represents the unknown displacements $u_{0}, v_{0}, w_{0}, \theta_{x}, \theta_{y}, \theta_{z}, \psi_{x}, \psi_{y}, \psi_{z}$, $\xi_{x}, \xi_{y}$, while $\left\{a_{i}(x, y)\right\}$ are column vectors of the Ritz approximation functions that satisfy the boundary conditions of the problem, and $\left\{q_{i}(t)\right\}$ are the column vectors of the Ritz coefficients to be determined.

\section{Equations of Motion}

The equations of motion will be derived using the Ritz approximation technique for the eleven deformation fields. Substituting Eq. (22). into Eq.(5), the strain vectors $\left\{\varepsilon^{0}\right\}^{T},\left\{\varepsilon^{1}\right\}^{T}$, $\left\{\varepsilon^{2}\right\}^{T}$, and $\left\{\varepsilon^{3}\right\}^{T}$ can be expressed in terms of the generalized coordinates $\left\{q_{i}\right\}$ as follows:

$$
\begin{array}{ll}
\left\{\varepsilon^{0}\right\}=\left[\bar{\varepsilon}^{0}(x, y)\right]\{q\}, & \left\{\varepsilon^{1}\right\}=\left[\bar{\varepsilon}^{1}(x, y)\right]\{q\}, \\
\left\{\varepsilon^{2}\right\}=\left[\bar{\varepsilon}^{2}(x, y)\right]\{q\}, & \left\{\varepsilon^{3}\right\}=\left[\bar{\varepsilon}^{3}(x, y)\right]\{q\}
\end{array}
$$

where $\{q\}$ is the generalized column vector of Ritz coefficients;

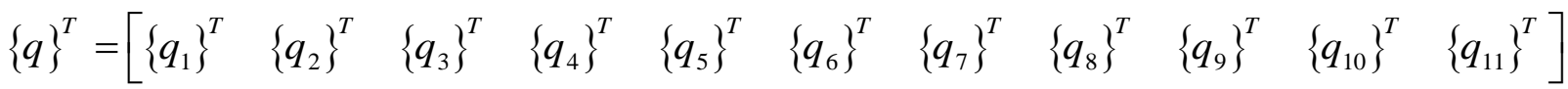

$\left[\bar{\varepsilon}^{0}(x, y)\right],\left[\bar{\varepsilon}^{1}(x, y)\right],\left[\bar{\varepsilon}^{2}(x, y)\right]$, and $\left[\bar{\varepsilon}^{3}(x, y)\right]$ are given in Appendix (B).

Substituting from Eq.(23) to Eq.(12), the virtual strain energy can be written as follows

$$
\delta U=\delta\{q(t)\}^{T}[K]\{q(t)\}
$$

where $[K]$ is the stiffness matrix of the laminate.

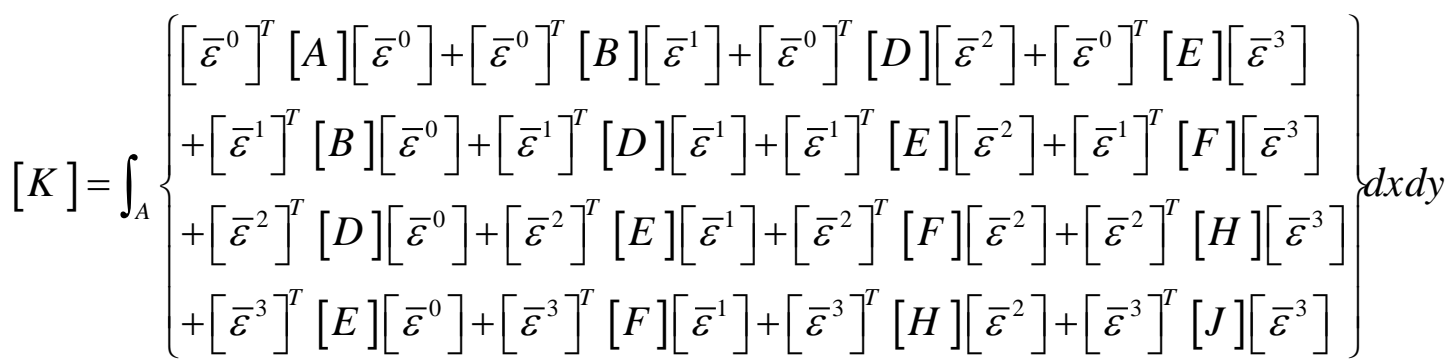

Substituting for the assumed displacement functions from Eq.(22) into Eq. (14), the virtual work $\delta V$ done by the applied forces can be written as,

$$
\delta V=\int_{A}\left\{p_{z}(x, y) \delta\left\{q_{3}\right\}^{T}\left\{a_{3}(x, y)\right\}\right\} d x d y+F_{z i} \delta\left\{q_{3}\right\}^{T}\left\{a_{3}\left(x_{i}, y_{i}\right)\right\}
$$

Or

$$
\delta V=\delta\{q\}^{T}\left(\{F\}+\left\{F_{0}\right\}\right)
$$

where $\{F\}$ and $\left\{F_{0}\right\}$ are the distributed and concentrated load vectors, respectively, with the following expressions

$$
\begin{aligned}
& \{F\}^{T}=\int_{A}\left[\begin{array}{lllllllllll}
0 & 0 & p_{z}(x, y)\left\{a_{3}\right\}^{T} & 0 & 0 & 0 & 0 & 0 & 0 & 0 & 0
\end{array}\right] d x d y \\
& \left\{F_{0}\right\}^{T}=\left[\begin{array}{lllllllllll}
0 & 0 & F_{z i}\left\{a_{3}\left(x_{i}, y_{i}\right)\right\}^{T} & 0 & 0 & 0 & 0 & 0 & 0 & 0 & 0
\end{array}\right]
\end{aligned}
$$

Substituting for the assumed displacement functions from Eq.(22) into Eq.(19), we get 


$$
\begin{aligned}
& \left\{U^{0}\right\}=\left[\bar{U}^{0}(x, y)\right]\{q(t)\} \\
& \left\{U^{1}\right\}=\left[\bar{U}^{1}(x, y)\right]\{q(t)\} \\
& \left\{U^{2}\right\}=\left[\bar{U}^{2}(x, y)\right]\{q(t)\} \\
& \left\{U^{3}\right\}=\left[\bar{U}^{3}(x, y)\right]\{q\}(t)
\end{aligned}
$$

where $\left[\bar{U}^{0}(x, y)\right],\left[\bar{U}^{1}(x, y)\right],\left[\bar{U}^{2}(x, y)\right]$, and $\left[\bar{U}^{3}(x, y)\right]$ are given in Appendix (B) Substituting from Eq.(30) in Eq.(20), the virtual kinetic energy, $\delta K$, can be written as

$$
\delta K=\delta\{\dot{q}(t)\}^{T}[M]\{\dot{q}(t)\}
$$

where $[M]$ is the mass matrix of the laminate

$$
[M]=\int_{A}\left(\begin{array}{l}
I_{0} \delta\left[\bar{U}^{0}\right]^{T}\left[\bar{U}^{0}\right]+I_{1} \delta\left[\bar{U}^{0}\right]^{T}\left[\bar{U}^{1}\right]+I_{2} \delta\left[\bar{U}^{0}\right]^{T}\left[\bar{U}^{2}\right]+I_{3} \delta\left[\bar{U}^{0}\right]^{T}\left[\bar{U}^{3}\right] \\
+I_{2} \delta\left[\bar{U}^{2}\right]+I_{2} \delta\left[\bar{U}^{1}\right]^{T}\left[\bar{U}^{1}\right]+I_{3} \delta\left[\bar{U}^{1}\right]^{T}\left[\bar{U}^{2}\right]+I_{4} \delta\left[I_{3} \delta\left[\bar{U}^{2}\right]^{T}\left[\bar{U}^{3}\right]\right. \\
+I_{3} \delta\left[\bar{U}^{3}\right]^{T}\left[\bar{U}^{0}\right]+I_{4} \delta\left[I_{4} \delta\left[\bar{U}^{2}\right]^{T}\left[\bar{U}^{2}\right]+I_{5} \delta\left[\bar{U}^{2}\right]+I_{5} \delta\left[\bar{U}^{3}\right]^{T}\left[\bar{U}^{3}\right]\right.
\end{array}\right] d x d y
$$

Finally, the equations of motion of the plate are represented by

$$
[M]\{\ddot{q}\}+[K]\{q\}=\{F\}+\left\{F_{0}\right\}
$$

where $[K]$ is the stiffness matrix, $[M]$ is the mass matrix, $\{F\}$, and $\left\{F_{0}\right\}$ are the distributed and concentrated load vectors given in Eq.(29), and the unknowns $\{q\}$ are the Ritz coefficients to be determined.

\section{Boundary Conditions}

In Ritz solution technique, the boundary conditions are satisfied by appropriate choice of the Ritz functions. Two special cases of plate boundary conditions, simply supported and cantilever plates, will be discussed here.

For simply supported plate, the boundary conditions along $(\mathrm{x}=0, \mathrm{a})$ edges are $v_{0}, \frac{\partial w_{0}}{\partial y}, \theta_{y}, \psi_{y}, \xi_{y}, w_{0}$, and $\frac{\partial^{2} w_{0}}{\partial x^{2}}$ are all equal to zero, and along $(\mathrm{y}=0, \mathrm{~b})$ edges are $u_{0}, \frac{\partial w_{0}}{\partial x}, \theta_{x}, \psi_{x}, \xi_{x}, w_{0}$, and $\frac{\partial^{2} w_{0}}{\partial y^{2}}$ are all equal to zero.

An appropriate choice of simple polynomials for Ritz function series can reflect the geometric and loading boundary conditions. The minimum order of transverse displacement that satisfies the previous boundary conditions is;

$$
w_{0}(x, y)=C \bar{X} \bar{Y}
$$

where $\quad \bar{X}=\left(x-\frac{2}{a^{2}} x^{3}+\frac{x^{4}}{a^{3}}\right), \quad \bar{Y}=\left(y-\frac{2}{b^{2}} y^{3}+\frac{y^{4}}{b^{3}}\right)$

After making a convergence test to Case (I) given below, by increasing the number of terms of $w_{0}, 6$ terms were found to be accurate enough. The total number of degrees of freedom will be eighteen.

$$
w_{0}=C_{w 1} \bar{X} \bar{Y}+C_{w 2} \bar{X}^{2} \bar{Y}+C_{w 3} \bar{X} \bar{Y}^{2}+C_{w 4} \bar{X}^{2} \bar{Y}^{2}+C_{w}{ }_{5} \bar{X}^{3} \bar{Y}+C_{w 6} \bar{X} \bar{Y}^{3}
$$


The other displacement functions are chosen such that they satisfy boundary conditions. The used column vectors of the approximation functions for simply supported boundary conditions $\left\{a_{i}(x, y)\right\}$ are given in Appendix (C).

For cantilever plate, imposing fixed boundary conditions along $(\mathrm{x}=0)$ edge, the geometric boundary conditions along that edge are $u_{0}, v_{0}, w_{0}, \frac{\partial w_{0}}{\partial x}, \frac{\partial v_{0}}{\partial x}, \theta_{x}, \psi_{x}, \xi_{x}, \theta_{y}, \psi_{y}$, and $\xi_{y}$ are all equal to zero.

An appropriate choice of simple polynomials for Ritz function series can reflect the above geometric boundary conditions. After making a convergence test in Case (II), by increasing the number of terms of $w_{0}$, a nine-term simple polynomial was found to be accurate enough to represent the transverse displacement $w_{0}$. This polynomial is formed by multiplying three terms in $\mathrm{x}$ by three terms in $\mathrm{y}$ to give nine terms of $w_{0}$ and the total DOF of the plate will be 49, as follows

$$
\begin{aligned}
w_{0}(x, y)= & C_{w 1} x^{2}+C_{w 2} x^{2} y+C_{w 3} x^{3}+C_{w 4} x^{2} y^{2}+C_{w 5} x^{3} y \\
& +C_{w 6} x^{4}+C_{w 7} x^{3} y^{2}+C_{w 8} x^{4} y+C_{w 9} x^{4} y^{2}
\end{aligned}
$$

The other displacement functions are chosen such that they satisfy the same boundary conditions. The used column vectors of the Ritz approximation functions for a cantilever plate $\left\{a_{i}(x, y)\right\}$ are given in Appendix (C).

\section{Numerical Results and Discussion}

To validate the proposed model, the static deflection and fundamental natural frequency results are presented and compared with other published models for both isotropic and laminated composite plates with simply supported and cantilevered boundary conditions. A laminated composite simply supported plate subjected to static double sinusoidal load is discussed first. Then, an isotropic cantilever plate subjected to a uniform distributed load is presented. The static response and fundamental frequencies are calculated for laminated composite cantilever plates.

\subsection{Case (I): Simply supported laminated composite plate (static response)}

A three-layer $\left(0^{\circ} / 90^{\circ} / 0^{\circ}\right)$, simply supported square plate of three different side-to-thickness ratios $\lambda=L / t=(10,20,100)$ is analyzed. The material properties of the used composite lamina are given below in Table 1 .

Table 1. Material properties of the composite lamina

\begin{tabular}{c|c|c|c|c}
\hline \hline $\mathbf{E}_{\mathbf{1 1}}$ & $\mathbf{E}_{\mathbf{2 2}}=\mathbf{E}_{\mathbf{3 3}}$ & $\mathbf{G}_{\mathbf{1 2}}=\mathbf{G}_{\mathbf{1 3}}$ & $\mathbf{G}_{\mathbf{2 3}}$ & $\mathbf{v}_{\mathbf{1 2}}=\mathbf{v}_{\mathbf{1 3}}=\mathbf{v}_{\mathbf{2} 3}$ \\
\hline $172.4 \mathrm{GPa}$ & $6.9 \mathrm{GPa}$ & $3.45 \mathrm{GPa}$ & $1.38 \mathrm{GPa}$ & 0.25 \\
\hline \hline
\end{tabular}

The applied double sinusoidal load function is $q=q_{0} \sin \frac{\pi x}{a} \sin \frac{\pi y}{b}(a=b=L)$.

The convergence of the obtained results to the exact values for deflection $(w)$ and stress $\left(\sigma_{x}\right)$ at the plate center are shown in Fig. 1 and Fig. 2, respectively, using various Pascal triangle polynomials composed of multiplication of $\bar{X}$ and $\bar{Y}$, the elementary shape functions that satisfy the simply supported boundary conditions, Eq.(35). 
According to this convergence study, six degrees of freedom were used to represent the transverse deflection $w_{0}(x, y)$, with a total of 18 degrees of freedom for the plate, Appendix (C). Results are given in normalized quantities where

$$
\begin{aligned}
& \left(\bar{\sigma}_{x}, \bar{\sigma}_{y}, \bar{\tau}_{x y}\right)=\frac{1}{q_{0} \lambda^{2}}\left(\sigma_{x}, \sigma_{y}, \tau_{x y}\right), \bar{w}=\frac{\pi^{4} Q}{12 \lambda^{4} t q_{0}} w, \lambda=\frac{a}{t}, Q=4 G_{12}+\frac{E_{11}+E_{22}\left(1+2 v_{12}\right)}{\left(1-v_{12} v_{21}\right)}, \\
& \delta_{\max }=\bar{w}(a / 2, a / 2,0), \quad \sigma_{1}=\bar{\sigma}_{x}(a / 2, a / 2, \pm t / 2), \quad \sigma_{2}=\bar{\sigma}_{y}(a / 2, a / 2, \pm t / 4), \quad \text { and } \\
& \tau=\bar{\tau}_{x y}(0,0, \pm t / 2) .
\end{aligned}
$$

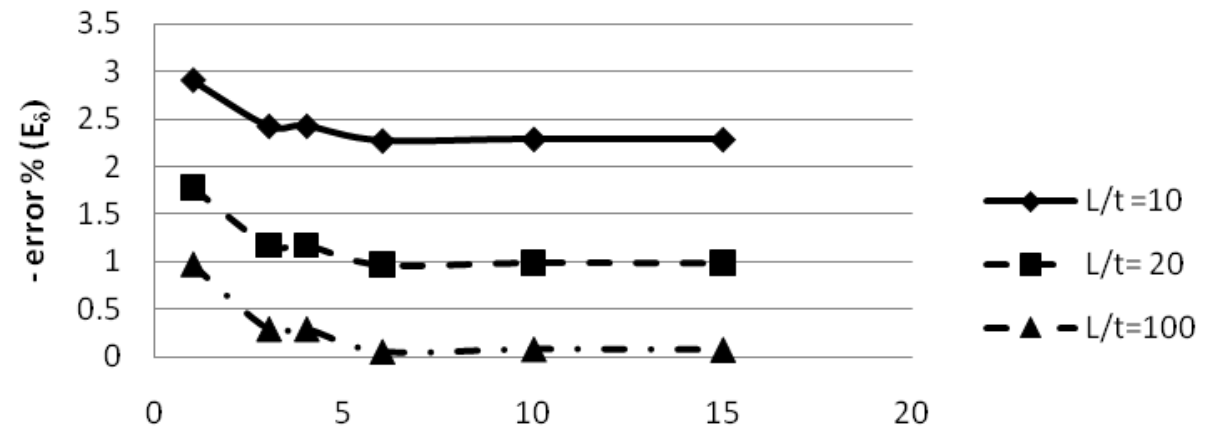

No. of Degrees of Freedom of transverse deformation (w)

Fig. 1. Convergence of mid-point deflection $\left(\delta_{\max }\right)$

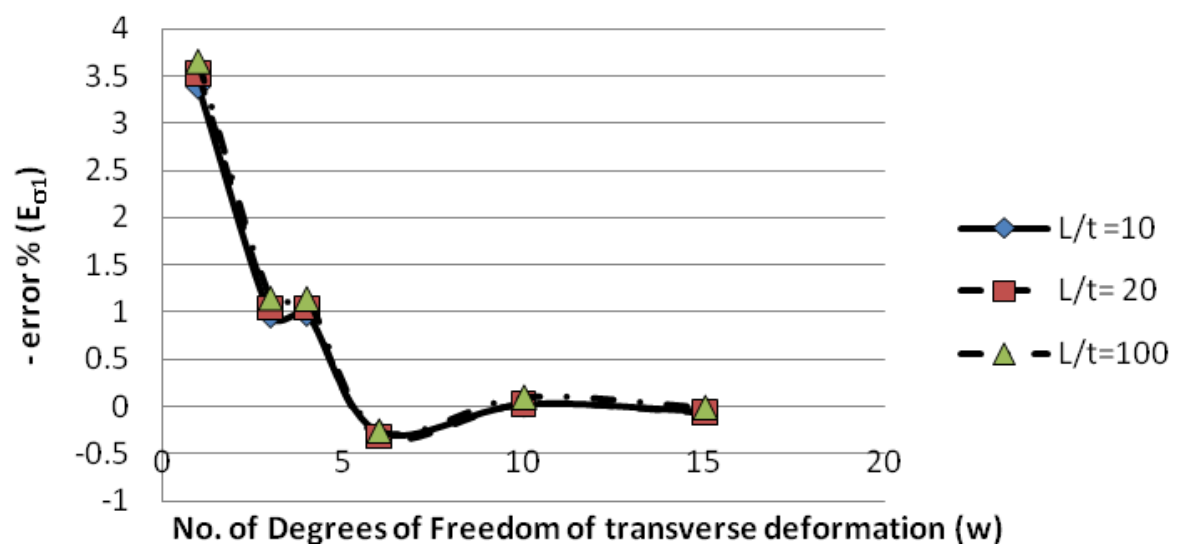

Fig. 2. Convergence of mid-point normal stress $\left(\sigma_{1}\right)$

Table 2. gives values of $\delta_{\max }, E_{\delta}, \sigma_{1}, E_{\sigma_{1}}, \sigma_{2}, E_{\sigma_{2}}, \tau$, and $E_{\tau}$ calculated by the present model in comparison with the available published results. $E_{\delta}$ is the percentage error in $\delta_{\max }$ from the exact value, $E_{\sigma_{1}}$ is the percentage error in $\sigma_{1}, E_{\sigma_{2}}$ is the percentage error in $\sigma_{2}$, and $E_{\tau}$ is the percentage error in $\tau$. The comparison shows good agreement with the exact solutions.

It is important now to highlight the advantages of the present Modified Higher Order Shear Deformation Theory over other theories listed in Table 1. The same procedure of Ritz solution technique was followed using different displacement field theories, Eq.(1).The convergences of all theories are shown in Fig. 3 and Fig. 4. It is clear from the figures that the present Modified Higher Order Shear Deformation Theory is the most accurate, and the fastest theory to converge to the exact solution. Another important notice, is that the results of the FSDT and SPT are exactly the same. So, the second order terms $z^{2} \psi_{x}$, and $z^{2} \psi_{y}$ in the 
in-plane displacement filed equations, have no effect in this case. The reason for this is that it is a symmetric lamination case. Also, it is notable that FSDT, SPT, and Lo HPT have very poor convergence performance. These theories don't contain the $w_{0}$-derivative terms, $-z \frac{\partial w_{0}(x, y, t)}{\partial x}$ and $-z \frac{\partial w_{0}(x, y, t)}{\partial y}$, in the in-plane displacement field equations, Eq.(1), and Table 1. In conclusion, the MHSDT is the most convenient theory to provide the best solutions with minimum computational time.

Table 2. Three layer cross-ply $\left(0^{\circ} / 90^{\circ} / 0^{\circ}\right)$ square plate under double sinusoidal loading

\begin{tabular}{|c|c|c|c|c|c|c|c|c|c|}
\hline & Reference & $\delta_{\max }$ & $E_{\delta}$ & $\sigma_{1}$ & $E_{\sigma_{1}}$ & $\sigma_{2}$ & $E_{\sigma_{2}}$ & $\tau$ & $E_{\tau}$ \\
\hline \multirow{9}{*}{ 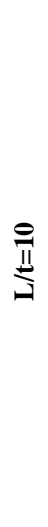 } & A (exact) & 1.709 & 0 & 0.559 & 0 & 0.403 & 0 & 0.0276 & 0 \\
\hline & B (present) & 1.67017 & -2.272088941 & 0.560537 & 0.274955277 & 0.391707 & -2.802233251 & 0.0273232 & -1.002898551 \\
\hline & $\mathrm{C}$ & 1.534 & -10.23990638 & 0.484 & -13.41681574 & 0.35 & -13.15136476 & - & - \\
\hline & $\mathrm{D}$ & 1.448 & -15.27208894 & 0.532 & -4.830053667 & 0.307 & -23.82133995 & 0.025 & -9.420289855 \\
\hline & $\mathrm{E}$ & 2.034 & 19.01696899 & 0.542 & -3.041144902 & - & - & 0.0292 & 5.797101449 \\
\hline & $\mathrm{F}$ & 1.727 & 1.053247513 & 0.493 & -11.80679785 & 0.407 & 0.992555831 & - & - \\
\hline & G & 1.714 & 0.292568754 & 0.554 & -0.894454383 & 0.397 & -1.488833747 & 0.0273 & -1.086956522 \\
\hline & $\mathrm{H}$ & 1.468 & -14.10181393 & 0.577 & 3.220035778 & 0.318 & -21.09181141 & 0.0247 & -10.50724638 \\
\hline & I & 1 & -41.48624927 & 0.539 & -3.577817531 & 0.269 & -33.25062035 & 0.0213 & -22.82608696 \\
\hline \multirow{9}{*}{ 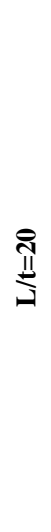 } & A (exact) & 1.189 & 0 & 0.543 & 0 & 0.309 & 0 & 0.023 & 0 \\
\hline & $\mathrm{B}$ (present) & 1.17751 & -0.966358284 & 0.54472 & 0.316758748 & 0.305828 & -1.026537217 & 0.0229627 & -0.162173913 \\
\hline & $\mathrm{C}$ & 1.136 & -4.457527334 & 0.511 & -5.893186004 & 0.287 & -7.1197411 & - & - \\
\hline & $\mathrm{D}$ & 1.114 & -6.307821699 & 0.557 & 2.578268877 & 0.307 & -0.647249191 & 0.0231 & 0.434782609 \\
\hline & $\mathrm{E}$ & 1.273 & 7.064760303 & 0.546 & 0.552486188 & - & - & 0.0239 & 3.913043478 \\
\hline & $\mathrm{F}$ & 1.191 & 0.168208579 & 0.533 & -1.841620626 & 0.312 & 0.970873786 & - & - \\
\hline & G & 1.191 & 0.168208579 & 0.538 & -0.920810313 & 0.3085 & -0.161812298 & 0.02297 & -0.130434783 \\
\hline & $\mathrm{H}$ & 1.119 & -5.887300252 & 0.556 & 2.394106814 & 0.284 & -8.090614887 & 0.0224 & -2.608695652 \\
\hline & I & 1 & -15.89571068 & 0.539 & -0.73664825 & 0.269 & -12.94498382 & 0.0213 & -7.391304348 \\
\hline \multirow{9}{*}{ 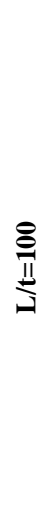 } & A (exact) & 1.008 & 0 & 0.539 & 0 & 0.271 & 0 & 0.0214 & 0 \\
\hline & B (present) & 1.00746 & -0.053571429 & 0.540375 & 0.255102041 & 0.27159 & 0.217712177 & 0.0213583 & -0.194859813 \\
\hline & $\mathrm{C}$ & 1.005 & -0.297619048 & 0.523 & -2.968460111 & 0.263 & -2.95202952 & - & - \\
\hline & $\mathrm{D}$ & 1.003 & -0.496031746 & 0.566 & 5.009276438 & 0.284 & 4.79704797 & 0.0223 & 4.205607477 \\
\hline & $\mathrm{E}$ & 1.015 & 0.694444444 & 0.551 & 2.226345083 & - & - & 0.0219 & 2.336448598 \\
\hline & $\mathrm{F}$ & 0.999 & -0.892857143 & 0.537 & -0.371057514 & 0.265 & -2.21402214 & - & - \\
\hline & G & 0.997 & -1.091269841 & 0.523 & -2.968460111 & 0.263 & -2.95202952 & 0.02089 & -2.38317757 \\
\hline & $\mathrm{H}$ & 1.004 & -0.396825397 & 0.543 & 0.742115028 & 0.267 & -1.47601476 & 0.0215 & 0.46728972 \\
\hline & I & 1 & -0.793650794 & 0.539 & 0 & 0.269 & -0.73800738 & 0.0213 & -0.46728972 \\
\hline
\end{tabular}

(A) exact solution by Pagano and Hatfield, [12],

(B) present Modified higher order plate model,

(C) a finite element solution made by Reddy, [31],

(D) a finite element solution by Panda and Natarajan, [32],

(E) a FE solution by Mawenya and Davies, [33]

(F) Ref. Moser et al. [34],
(G) a FE solution using a higher order shear deformation theory by Phan and Reddy, [19],

(H) Ref. Dey, using a simple finite element [17],

(I) the classical plate theory. 


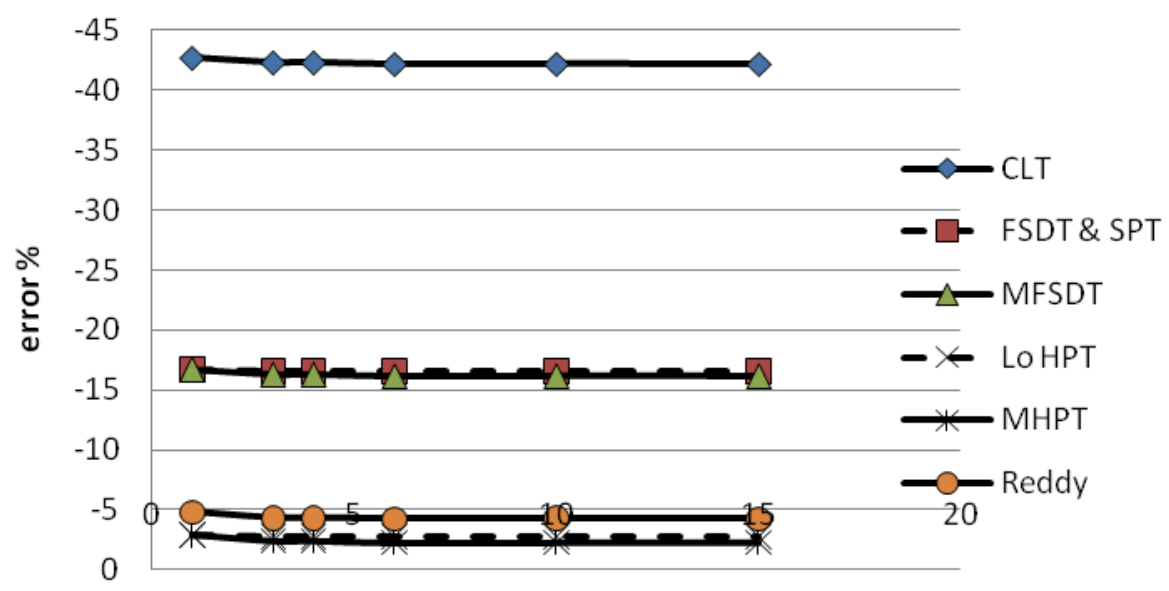

No. of Degrees of Freedom of transverse deformation (w)

Fig. 3. Convergence of mid-point deflection $\left(\delta_{\max }\right)$ using different theories for simply supported plate $(\mathrm{L} / \mathrm{t}=10)$

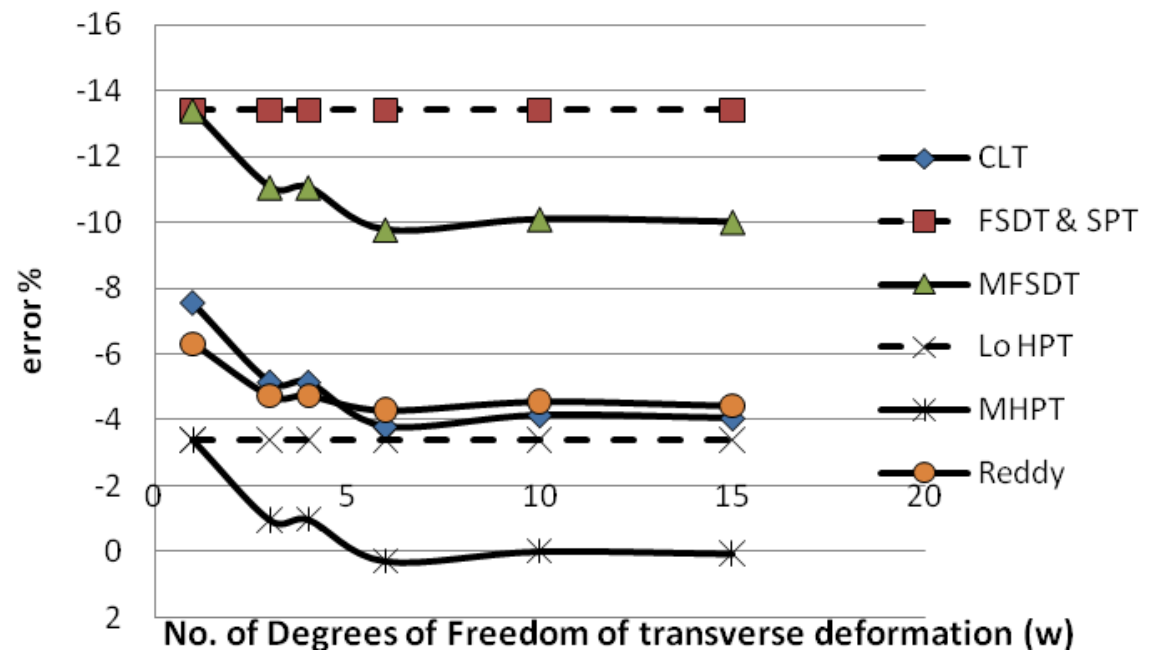

Fig. 4. Convergence of mid-point stress $\left(\sigma_{1}\right)$ using different theories for simply supported plate $(\mathrm{L} / \mathrm{t}=10)$

\subsection{Case (II): Simply Supported laminated composite plate (natural frequency)}

Fundamental frequency of simply supported bidirectional, multilayered square $(a=b=L)$ crossply laminated plates consisting of a large number of symmetric and anti-symmetric layers is obtained. The plates side-to-thickness ratio $\lambda=L / h=5$ The effect of varying degree of orthotropy and number of layers are considered. Fiber orientations of different laminae alternate between $0^{\circ}$ and $90^{\circ}$ w.r.t. $x$-axis. In symmetrical case, the $0^{0}$ layers are at the outer surfaces of the laminate. Total thickness of the $0^{\circ}$ and $90^{\circ}$ layers in each laminate are the same.

The degree of orthotropy is varied between 3 and 40; the number of layers used are 2, 3, 4, 5, 6,9 , and 10. The material properties of the individual layers are given in Table 3 .

Table 3. Material constants of the individual layers

\begin{tabular}{c|c|c}
\hline \hline $\mathbf{G}_{\mathbf{1 2}} / \mathbf{E}_{\mathbf{2 2}}=\mathbf{G}_{\mathbf{1 3}} / \mathbf{E}_{\mathbf{2 2}}$ & $\mathbf{G}_{\mathbf{2 3}} / \mathbf{E}_{\mathbf{2 2}}$ & $\mathbf{v}_{\mathbf{1 2}}=\mathbf{v}_{\mathbf{1 3}}=\mathbf{v}_{\mathbf{2 3}}$ \\
\hline 0.6 & 0.5 & 0.25 \\
\hline \hline
\end{tabular}


Results are presented in Table 4. (a) for symmetric case, and (b) for the antisymmetric case. $\bar{\omega}$ is the non-dimensional natural frequency, $\bar{\omega}=10 \omega \sqrt{\frac{\rho h}{E_{22}}} . \Delta \%$ is the percentage error relative to the exact solution derived by Noor [13]. Ghosh [18], used a simple finite element based on higher order theory to calculate the fundamental frequencies of laminated composite plate. A refined analysis of laminated plates by finite element displacement methods was made by Owen [35] . In the present model, the shape functions used are the same as in the previous case. It is clear from Table 4 that the obtained results are very comparable with other available results.

\subsection{Case (III): Cantilever isotropic plate (static response)}

An isotropic square plate $(\mathrm{a}=\mathrm{b}=\mathrm{L})$ with side-to-thickness ratio $\lambda=L / h=100$ is analyzed. A Poisson's ratio $(v)$ of 0.3 is adopted for the plate material. A transverse uniform load $\left(\mathrm{q}_{0}\right)$ is applied.

In order to find suitable shape functions for the cantilever plate, the unknown displacements $u_{0}, v_{0}, \theta_{x}, \theta_{y}, \theta_{z}, \psi_{x}, \psi_{y}, \psi_{z}, \xi_{x}, \xi_{y}$ are approximated by the x-y-dependent functions, listed in Appendix (C). The transverse deflection $w_{0}$ approximate functions are alternated such that the number of terms of $w_{0}$ are increased from 1 to 49 , and the total degrees of freedom are raised from 41 to 89 . These approximate functions are the result of multiplication of two polynomials in $\mathrm{x}$ and $\mathrm{y}$ directions that satisfy the geometric boundary conditions mentioned before, using Pascal triangle.

The convergence of the normalized maximum deflection $(\bar{w})$ and normalized stress-resultants $\left(\bar{M}_{x}\right.$ and $\left.\bar{M}_{y}\right)$ are given in Fig. 5. Results are given in normalized quantities as $\left(\bar{M}_{x}, \bar{M}_{y}, \bar{M}_{x y}\right)=\frac{10^{4}}{q_{0} a^{2}}\left(M_{x}, M_{y}, M_{x y}\right)$ and $\bar{w}=\frac{10^{4} E_{11} h^{3}}{a^{4} q_{0}} w_{0}$.

Using three-term polynomials gives acceptable accuracy, as seen in Fig. 5. Moreover, after the three-term polynomials, the stiffness matrix becomes ill conditioned, and the numerical solution begins to have a significant error. Thus, three-term polynomials are used in $\mathrm{x}$ and $\mathrm{y}$ directions to represent the transverse deflection $w_{0}(x, y)$, which gives 49 total degrees of freedom.

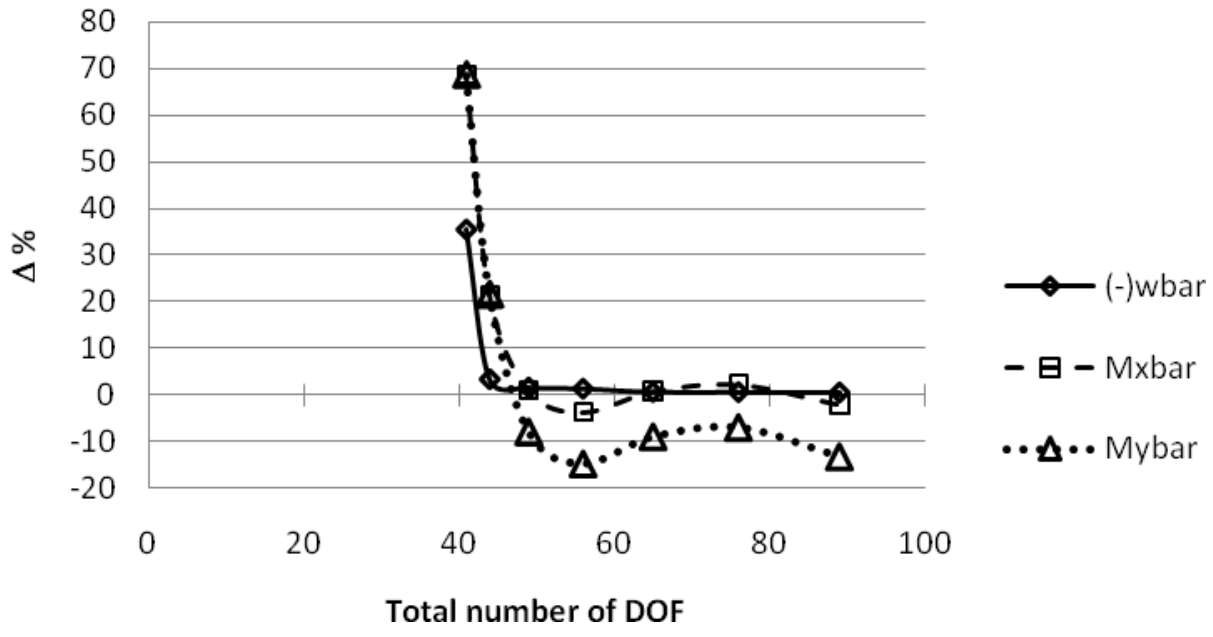

Fig. 5. Convergence of the normalized maximum deflection $\bar{w}$, and stress resultants, $\bar{M}_{x}, \bar{M}_{y}$ at $\mathbf{x}=\mathbf{0}, \mathbf{y}=\mathrm{b} / 2$ 
Table 4. Effect of degree of orthotropy of the individual layers on the fundamental frequency of simply supported square multi-layered composite plate with $h / L=0.2$

\section{a. Symmetric Case}

\begin{tabular}{|c|c|c|c|c|c|c|c|c|c|c|c|}
\hline \multirow{3}{*}{ Source } & \multirow{3}{*}{ No. of layers } & \multicolumn{10}{|c|}{$\mathbf{E}_{1} / \mathbf{E}_{2}$} \\
\hline & & \multicolumn{2}{|c|}{3} & \multicolumn{2}{|c|}{10} & \multicolumn{2}{|c|}{20} & \multicolumn{2}{|c|}{30} & \multicolumn{2}{|c|}{40} \\
\hline & & $\bar{\omega}$ & $\Delta \%$ & $\bar{\omega}$ & $\Delta \%$ & $\bar{\omega}$ & $\Delta \%$ & $\bar{\omega}$ & $\Delta \%$ & $\bar{\omega}$ & $\Delta \%$ \\
\hline Noor [13] & \multirow{5}{*}{$\begin{array}{c}3 \\
(0 / 90 / 0)\end{array}$} & 2.6474 & & 3.2841 & & 3.8241 & & 4.1089 & & 4.3006 & \\
\hline Present model & & 2.62723 & -0.762 & 3.2655 & -0.566 & 3.69709 & -3.321 & 3.9396 & -4.1203 & 4.10269 & -4.601 \\
\hline Ghosh [18] & & 2.64 & -0.28 & 3.39 & 3.2246 & 3.92 & 2.5078 & 4.25 & 3.4340 & 4.47 & 3.9389 \\
\hline Owen [35] & & 2.6948 & 1.7904 & 3.3917 & 3.2764 & 3.8979 & 1.9299 & 4.1941 & 2.0735 & 4.3951 & 2.1973 \\
\hline $\mathrm{CPT}$ & & 2.9198 & 10.289 & 4.1264 & 25.648 & 5.4043 & 41.322 & 6.4336 & 56.577 & 7.3196 & 70.199 \\
\hline Noor [13] & \multirow{5}{*}{$\begin{array}{c}5 \\
(0 / 90 / 0 / 90 / 0)\end{array}$} & 2.6587 & & 3.4089 & & 3.9792 & & 4.314 & & 4.5374 & \\
\hline Present model & & 2.64006 & \begin{tabular}{|l|}
-0.701 \\
\end{tabular} & 3.37278 & -1.06 & 3.92601 & -1.337 & 4.25266 & -1.421 & 4.47272 & -1.425 \\
\hline Ghosh [18] & & \begin{tabular}{|l|}
2.64 \\
\end{tabular} & -0.703 & 3.45 & 1.2057 & 4.06 & 2.0306 & 4.42 & 2.4571 & 4.67 & 2.9223 \\
\hline Owen [35] & & 2.6988 & 1.5083 & 3.4534 & 1.3054 & 4.0297 & 1.2691 & 4.3704 & 1.3073 & 4.5992 & 1.3620 \\
\hline $\mathrm{CPT}$ & & 2.9198 & 9.8206 & 4.1264 & 21.048 & 5.4043 & 35.814 & 6.4336 & 49.133 & 7.3196 & 61.317 \\
\hline Noor [13] & \multirow{5}{*}{$\begin{array}{c}9 \\
(0 / 90 / 0 / 90 / 0 / \\
90 / 0 / 90 / 0)\end{array}$} & 2.664 & & 3.4432 & & 4.0547 & & 4.421 & & 4.6679 & \\
\hline Present model & & 2.64446 & -0.733 & 3.41421 & -0.842 & 4.01746 & -0.918 & 4.37998 & -0.927 & 4.62559 & -0.906 \\
\hline Ghosh [18] & & \begin{tabular}{|l|}
2.64 \\
\end{tabular} & -0.901 & 3.47 & 0.7783 & 4.1 & 1.1172 & 4.48 & 1.3345 & 4.74 & 1.544 \\
\hline Owen [35] & & 2.6971 & 1.2425 & 3.4708 & 0.8016 & 4.0746 & 0.4908 & 4.436 & 0.3392 & 4.6803 & 0.265 \\
\hline $\mathrm{CPT}$ & & 2.9198 & 9.6021 & 4.1264 & 19.842 & 5.4043 & 33.285 & 6.4336 & 45.523 & 7.3196 & 56.807 \\
\hline
\end{tabular}

\section{b. Antisymmetric Case}

\begin{tabular}{|c|c|c|c|c|c|c|c|c|c|c|c|}
\hline \multirow{3}{*}{ source } & \multirow{3}{*}{ No. of layers } & \multicolumn{10}{|c|}{$\mathbf{E}_{1} / \mathbf{E}_{2}$} \\
\hline & & \multicolumn{2}{|c|}{3} & \multicolumn{2}{|c|}{10} & \multicolumn{2}{|c|}{20} & \multicolumn{2}{|c|}{30} & \multicolumn{2}{|c|}{40} \\
\hline & & $\bar{\omega}$ & $\Delta \%$ & $\bar{\omega}$ & $\Delta \%$ & $\bar{\omega}$ & $\Delta \%$ & $\bar{\omega}$ & $\Delta \%$ & $\bar{\omega}$ & $\Delta \%$ \\
\hline Noor [13] & \multirow{5}{*}{$\begin{array}{c}2 \\
(0 / 90)\end{array}$} & 2.5031 & & 2.7938 & & 3.0698 & & 3.2705 & & 3.425 & \\
\hline Present model & & 2.52517 & 0.881 & 2.88177 & 3.148 & 3.20543 & 4.418 & 3.44099 & 5.212 & 3.62404 & 5.811 \\
\hline Ghosh [18] & & 2.48 & -0.922 & 2.82 & 0.937 & 3.17 & 3.264 & 3.45 & 5.488 & 3.69 & 7.737 \\
\hline Owen [35] & & 2.5601 & 2.277 & 2.8712 & 2.770 & 3.1558 & 2.801 & 3.361 & 2.767 & 3.5185 & 2.729 \\
\hline $\mathrm{CPT}$ & & 2.7082 & 8.193 & 3.0968 & 10.84 & 3.5422 & 15.38 & 3.9335 & 20.27 & 4.2884 & 25.20 \\
\hline Noor [13] & \multirow{5}{*}{$\begin{array}{c}4 \\
(0 / 90 / 0 / 90)\end{array}$} & 2.6182 & & 3.2578 & & 3.7622 & & 4.066 & & 4.2719 & \\
\hline Present model & & 2.61391 & -0.163 & 3.28678 & 0.889 & 3.82322 & 1.621 & 4.1485 & 2.029 & 4.36924 & 2.278 \\
\hline Ghosh [18] & & \begin{tabular}{|l|}
2.6 \\
\end{tabular} & -0.695 & 3.32 & 1.909 & 3.9 & 3.662 & 4.27 & 5.017 & 4.53 & 6.041 \\
\hline Owen [35] & & 2.6691 & 1.944 & 3.325 & 2.062 & 3.8454 & 2.211 & 4.1612 & 2.341 & 4.3763 & 2.443 \\
\hline $\mathrm{CPT}$ & & 2.8676 & 9.525 & 3.8877 & 19.33 & 4.9907 & 32.65 & 5.89 & 44.85 & 6.669 & 56.11 \\
\hline Noor [13] & \multirow{5}{*}{$\begin{array}{c}6 \\
(0 / 90 / 0 / 90 / 0 / \\
90)\end{array}$} & 2.644 & & 3.3657 & & 3.9359 & & 4.2783 & & 4.5091 & \\
\hline Present model & & 2.63163 & -0.467 & 3.36602 & 0.009 & 3.94926 & 0.339 & 4.30125 & 0.5364 & 4.53941 & 0.6721 \\
\hline Ghosh [18] & & \begin{tabular}{|l|}
2.62 \\
\end{tabular} & -0.907 & 3.4 & 1.019 & 4.02 & 2.136 & \begin{tabular}{|l|}
4.4 \\
\end{tabular} & 2.844 & 4.66 & 3.346 \\
\hline Owen [35] & & 2.6839 & 1.509 & 3.4085 & 1.271 & 3.9758 & 1.013 & 4.3233 & 1.0518 & 4.5558 & 1.035 \\
\hline CPT & & 2.8966 & 9.553 & 4.0215 & 19.48 & 5.2234 & 32.71 & 6.1963 & 44.83 & 7.0359 & 56.03 \\
\hline Noor [13] & \multirow{5}{*}{$\begin{array}{c}10 \\
(0 / 90 / 0 / 90 / 0 / \\
90 / 0 / 90 / 0 / 90)\end{array}$} & 2.6583 & & 3.425 & & 4.0337 & & 4.4011 & & 4.6498 & \\
\hline Present model & & 2.64106 & -0.648 & 3.40905 & -0.465 & 4.02032 & -0.331 & 4.39032 & -0.244 & 4.64163 & -0.175 \\
\hline Ghosh [18] & & \begin{tabular}{|l|}
2.64 \\
\end{tabular} & -0.688 & 3.44 & 0.437 & 4.08 & 1.147 & 4.46 & 1.3383 & 4.72 & 1.509 \\
\hline Owen [35] & & 2.6916 & 1.252 & 3.4527 & 0.808 & 4.0526 & 0.468 & 4.414 & 0.2931 & 4.659 & 0.1978 \\
\hline CPT & & 2.9115 & 9.524 & 4.0888 & 19.38 & 5.3397 & 32.37 & 6.3489 & 44.257 & 7.2184 & 55.24 \\
\hline
\end{tabular}


Table 5. gives values of normalized deflection $\bar{w}$, and stress resultants $\bar{M}_{x}, \bar{M}_{y}$, and $\bar{M}_{x y}$ calculated by the present model in comparison with the available published results. The difference $(\Delta \%)$ mentioned in Table 5 . is the percentage difference in $\bar{w}$, and, $\bar{M}_{x}, \bar{M}_{y}$ relative to the reference values calculated by the finite element method using 2205 degrees of freedom, [24], listed in Table 5. with code FEM5. The comparison shows good agreement with the exact solutions.

Table 5. Normalized maximum deflection $\bar{w}$, and stress resultants $\bar{M}_{x}, \bar{M}_{y}$, and $\bar{M}_{x y}$ of isotropic cantilever plate

\begin{tabular}{|c|c|c|c|c|c|c|c|c|c|c|c|}
\hline \multirow{2}{*}{ Reference } & \multirow{2}{*}{ Code } & \multirow{2}{*}{$\begin{array}{l}\text { Total } \\
\text { DOF }\end{array}$} & \multicolumn{2}{|c|}{$\mathrm{x}=\mathbf{0}, \mathrm{y}=\mathrm{b} / 2$} & \multicolumn{2}{|c|}{$\mathrm{x}=\mathbf{0}, \mathrm{y}=\mathrm{b}$} & \multicolumn{5}{|c|}{$\mathrm{x}=\mathbf{0}, \mathrm{y}=\mathrm{b} / 2$} \\
\hline & & & $-\bar{w}$ & $\Delta \%$ & $-\bar{w}$ & $\Delta \%$ & $\bar{M}_{x}$ & $\Delta \%$ & $\bar{M}_{y}$ & $\Delta \%$ & $\bar{M}_{x y}$ \\
\hline $\begin{array}{c}\text { Present } \\
\text { model }\end{array}$ & PM & 49 & 13905 & 1.641084 & 13704.5 & 1.668221 & 5250.4 & 1.04787 & 1719.81 & -7.96045 & 0 \\
\hline \multirow{3}{*}{$\begin{array}{c}\text { Ritz } \\
\text { Method } \\
{[24]}\end{array}$} & RM1 & 108 & 14073 & 0.452713 & 13870 & 0.480735 & 5139 & 3.14738 & 1542 & 3.201507 & 0 \\
\hline & RM2 & 147 & 14085 & 0.367829 & 13884 & 0.380283 & 5355 & -0.92348 & 1607 & -0.87884 & 0 \\
\hline & PM3 & 192 & 14088 & 0.346608 & 13887 & 0.358757 & 5393 & -1.63965 & 1618 & -1.56937 & 0 \\
\hline \multirow{5}{*}{$\begin{array}{c}\text { Finite } \\
\text { Element } \\
\text { Method } \\
{[24]}\end{array}$} & FEM1 & 245 & 14164 & -0.19099 & 13941 & -0.0287 & 4438 & 16.35884 & 1331 & 16.44696 & 0 \\
\hline & FEM2 & 605 & 14148 & -0.07781 & 13939 & -0.01435 & 4765 & 10.196 & 1429 & 10.29504 & 0 \\
\hline & FEM3 & 2205 & 14143 & -0.04244 & 13940 & -0.02153 & 5031 & 5.182812 & 1509 & 5.27307 & 0 \\
\hline & FEM4 & 845 & 14116 & 0.148546 & 13917 & 0.143503 & 5232 & 1.394648 & 1578 & 0.94162 & 0 \\
\hline & FEM5 & 2205 & 14137 & 0 & 13937 & 0 & 5306 & 0 & 1593 & 0 & 0 \\
\hline
\end{tabular}

PM is the present model solution,

$\operatorname{RM}(1,2,3)$ are the Ritz solution using $(6,7,8)$ terms in the $\mathrm{x}$ and $\mathrm{y}$ directions for $u_{0}, v_{0}$, and $w_{0}$,

$\operatorname{FEM}(1,2,3,4,5)$ are the finite element solution using (72 three-noded, 200 three-noded, 800 three-noded, 72 six-noded, 200 six-noded) elements.

\subsection{Case (IV): Laminated Composite Cantilever plate (static response)}

A laminated composite square plate $(\mathrm{a}=\mathrm{b}=\mathrm{L})$ with side-to-thickness ratio $\lambda=L / h=100$ is analyzed. The material properties of the individual layers are given in Table 6 . The plate has symmetric lamination sequence, [0/90/0]. A transverse uniform load $\left(\mathrm{q}_{0}\right)$ is applied.

Table 6. Material constants of the individual layers

\begin{tabular}{|c|c|c|c|}
\hline $\mathbf{E}_{11} / \mathbf{E}_{22}$ & $\mathbf{E}_{33} / \mathbf{E}_{22}$ & $\mathbf{G}_{12} / \mathbf{E}_{22}=\mathbf{G}_{13} / \mathbf{E}_{22}=\mathbf{G}_{23} / \mathbf{E}_{22}$ & $v_{12}=v_{13}=v_{23}$ \\
\hline 15.4 & 1 & 0.5 & 0.3 \\
\hline
\end{tabular}

The same procedure of the previous problem is followed to get the convergence of the normalized maximum deflection $\bar{w}$, and stress resultants, $\bar{M}_{x}, \bar{M}_{y}$ as shown in Fig. 6.

Table 7. shows good agreement between the results calculated from the present model and those calculated using Ritz method and finite element method published in [24]. 


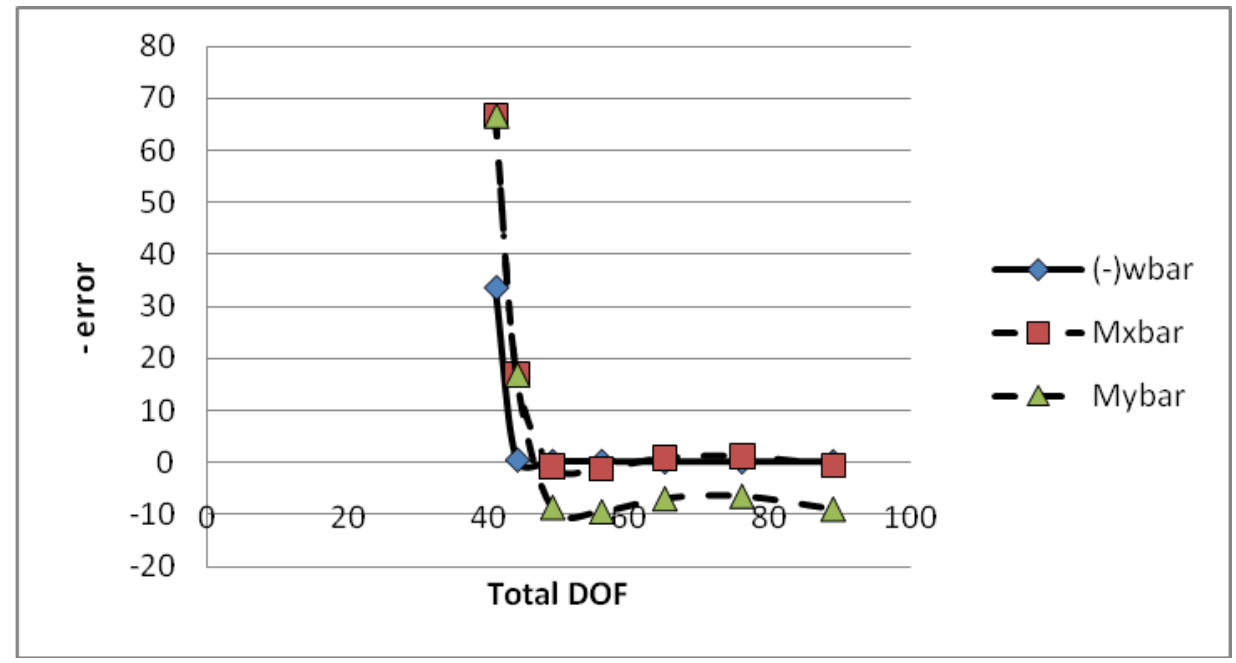

Fig. 6. Convergence of the normalized maximum deflection $\bar{w}$, and stress resultants,

$$
\bar{M}_{x}, \bar{M}_{y} \text { at } \mathbf{x}=\mathbf{0}, \mathbf{y}=\mathbf{b} / 2
$$

Table 7. Normalized maximum deflection $\bar{w}$, and stress resultants $\bar{M}_{x}, \bar{M}_{y}$, and $\bar{M}_{x y}$ of a laminated composite cantilever plate

\begin{tabular}{|c|c|c|c|c|c|c|c|c|c|c|c|}
\hline \multirow{2}{*}{ Reference } & \multirow{2}{*}{ Code } & \multirow{2}{*}{$\begin{array}{l}\text { Total } \\
\text { DOF }\end{array}$} & \multicolumn{2}{|c|}{$\mathrm{x}=0, \mathrm{y}=\mathrm{b} / 2$} & \multicolumn{2}{|c|}{$x=0, y=b$} & \multicolumn{5}{|c|}{$\mathrm{x}=0, \mathrm{y}=\mathrm{b} / 2$} \\
\hline & & & $-\bar{w}$ & $\Delta \%$ & $-\bar{w}$ & $\Delta \%$ & $\bar{M}_{x}$ & $\Delta \%$ & $\bar{M}_{y}$ & $\Delta \%$ & $\bar{M}_{x y}$ \\
\hline $\begin{array}{c}\text { Present } \\
\text { model }\end{array}$ & PM & 49 & 15502.8 & 0.348396 & 15377.2 & 0.413186 & 5058.5 & -0.70675 & 109.732 & -8.64554 & 0 \\
\hline \multirow{3}{*}{$\begin{array}{c}\text { Ritz } \\
\text { Method } \\
{[24]}\end{array}$} & RM1 & 108 & 15501 & 0.359967 & 15382 & 0.3821 & 4967 & 1.114872 & 100 & 0.990099 & 0 \\
\hline & RM2 & 147 & 15501 & 0.359967 & 15384 & 0.369147 & 5068 & -0.89588 & 102 & -0.9901 & 0 \\
\hline & RM3 & 192 & 15501 & 0.359967 & 15384 & 0.369147 & 5078 & -1.09496 & 102 & -0.9901 & 0 \\
\hline \multirow{5}{*}{$\begin{array}{c}\text { Finite } \\
\text { Element } \\
\text { Method } \\
{[24]}\end{array}$} & FEM1 & 245 & 15614 & -0.36639 & 15482 & -0.26553 & 4261 & 15.17022 & 86 & 14.85149 & 0 \\
\hline & FEM2 & 605 & 15582 & -0.1607 & 15459 & -0.11657 & 4552 & 9.376866 & 92 & 8.910891 & 0 \\
\hline & FEM3 & 2205 & 15567 & -0.06428 & 15449 & -0.05181 & 4786 & 4.718296 & 97 & 3.960396 & 0 \\
\hline & FEM4 & 845 & 15556 & 0.006428 & 15441 & 0 & 5006 & 0.338443 & 101 & 0 & 0 \\
\hline & FEM5 & 2205 & 15557 & 0 & 15441 & 0 & 5023 & 0 & 101 & 0 & 0 \\
\hline
\end{tabular}

\subsection{Case (V): Composite Cantilever plate (Natural Frequency)}

The fundamental frequencies are calculated for antisymmetric, cross-ply, rectangular laminated cantilever plates with varying aspect ratio (b/a), and side to thickness ratio (b/h), where $b$ is the length of the fixed edge. Material properties of the individual layers are given in Table 8. All the layers are assumed to have the same thickness.

Table 8. Material constants of the individual layers

\begin{tabular}{c|c|c|c|c}
\hline \hline $\mathbf{E}_{\mathbf{1 1}} / \mathbf{E}_{\mathbf{2 2}}$ & $\mathbf{E}_{\mathbf{3 3}} / \mathbf{E}_{\mathbf{2 2}}$ & $\mathbf{G}_{\mathbf{1 2}} / \mathbf{E}_{\mathbf{2 2}=} \mathbf{G}_{\mathbf{1 3}} / \mathbf{E}_{\mathbf{2 2}}$ & $\mathbf{G}_{\mathbf{2 3}} / \mathbf{E}_{\mathbf{2 2}}$ & $\boldsymbol{v}_{\mathbf{1 2}}=\mathbf{v}_{\mathbf{1 3}}=\mathbf{v}_{\mathbf{2 3}}$ \\
\hline 40 & 1 & 0.6 & 0.5 & 0.25 \\
\hline \hline
\end{tabular}


Using the approximate Ritz functions mentioned in Appendix $(\mathrm{C})$, the fundamental frequencies are calculated and listed in Table 9. The normalized natural frequency is given by $\bar{\omega}=\frac{\omega b^{2}}{h} \sqrt{\frac{\rho}{E_{22}}}$.

The obtained results are compared with other available published results, as shown in Table 9. Reddy [36], used CPT, FSDT, and HSDT to obtain the fundamental natural frequencies using finite element analysis. The shear correction factors for FSDT were taken to be 5/6. In the finite element analysis, a mesh of $2 \times 2$ for quadratic elements was used for the FSDT, and $4 \times 4$ mesh of 4-node elements was used for HSDT and CPT,[36]. The differences $\Delta \%$ are calculated relative to HSDT solution. The present model has good accuracy, especially for low aspect ratio (b/a) and high thickness ratio $(\mathrm{b} / \mathrm{h})$.

Table 9. Normalized fundamental frequencies of cantilever laminated plate [0/90]

\begin{tabular}{c|c|c|c|c|c|c|c}
\hline \multirow{2}{*}{ Model } & \multirow{2}{*}{$\mathbf{b} / \mathbf{h}$} & \multicolumn{2}{|c|}{$\mathbf{1}$} & \multicolumn{2}{|c}{$\mathbf{2}$} & \multicolumn{2}{|c}{$\mathbf{3}$} \\
\cline { 3 - 8 } & & $\bar{\omega}$ & $\Delta \%$ & $\bar{\omega}$ & $\Delta \%$ & $\bar{\omega}$ & $\Delta \%$ \\
\cline { 3 - 8 } & & 2.54126 & -0.770778 & 9.41426 & -1.92248 & 19.0827 & -3.78071 \\
\hline $\begin{array}{c}\text { Present } \\
\text { model }\end{array}$ & 10 & 2.61513 & -0.859476 & 10.4514 & -0.826705 & 23.4808 & -0.785059 \\
\hline \multirow{2}{*}{ CPT [36] } & 10 & 2.625 & 2.49902 & 10.4588 & 8.95945 & 23.3775 & 17.8747 \\
\cline { 2 - 8 } & 100 & 2.6285 & -0.35256 & 10.5138 & -0.23437 & 23.6548 & -0.04985 \\
\hline FSDT & 10 & 2.5334 & -1.07770 & 9.3501 & -2.59094 & 18.8491 & -4.95852 \\
\cline { 2 - 8 }$[36]$ & 100 & 2.6103 & -1.04253 & 10.4318 & -1.01247 & 23.4354 & -0.9769 \\
\hline HSDT & 10 & 2.561 & 0 & 9.5988 & 0 & 19.8325 & 0 \\
\cline { 2 - 8 }$[36]$ & 100 & 2.6378 & 0 & 10.5385 & 0 & 23.6666 & 0 \\
\hline \hline
\end{tabular}

\section{Conclusion and Future Work}

The static response and fundamental natural frequency of thick isotropic and composite plates with different boundary conditions were investigated. Lo's higher order plate theory is modified to get more accurate results. The obtained results proved that the Modified Higher Order Shear Deformation Theory has superiority over other theories. The obtained results showed a great match of the deflections, stresses, and natural frequencies for thin and thick plates. It is shown that using less number of degrees of freedom for Ritz solution, the obtained results are matched with the published data, which save computational time. It is also clear that the present theory is efficient for both thin and thick plates made of either isotropic or composite materials.

The fact that all Ritz approximation functions are simple polynomials leads to some desirable properties of formulation and solving techniques. However, it also leads to ill conditioning of the stiffness and mass matrices when high order polynomials are used. Extensive trials using different polynomials Ritz approximation functions are executed to make the convergence of the results before the static solution or eigenvlaue solution becomes ill conditioned.

In the future, geometric nonlinearity can be added to model large deformation problems and aeroelasticity modeling. 


\section{References}

[1] E. Reissner, "The effect of transverse shear deformation on the bending of elastic plates," Journal of Applied Mechanics, Vol. 12, No. 2, Trans. ASME Vol.67, pp. 69-77, June 1945.

[2] R. D. Mindlin, "Influence of rotary inertia and shear on flexural motion of isotropic, elasic plates," Journal of Applied Mechanics, Vol. 18, No.1, Trans. ASME Vol. 73, pp. 31-38, Mar. 1951.

[3] J. N. Reddy, An introduction to nonlinear finite element analysis: Oxford.

[4] G. L. Giles, "Equivalent plate modeling of conceptual Design of aircraft wing structures," AIAA Paper 1995-3945, Sept. 1995.

[5] E. Livne and I. Navarro, "Nonlinear equivalent plate modeling of wing-box structures," Journal of Aircraft, vol. 36, pp. 851-865, 1999.

[6] F. B. Hildebrand, E. Reissner, and G. B. Thomas, "Notes on the foundations of the theory of small displacements of orthotropic shells," NACA T.N. No. 1833, 1949.

[7] J. N. Reddy, Mechanics of laminated composite plates and shells, second ed.: CRC Press, 2004.

[8] K. H. Lo, R. M. Christensen, and E. M. Wu, "A high-order theory of plate deformation, Part 1: Homogeneous plates," Journal of Applied Mechanics, vol. 44, Trans. ASME, Vol. 99, Series E, pp. 663-668, December 1977.

[9] K. H. Lo, R. M. Christensen, and E. M. Wu, "A high-order theory of plate deformation, Part 2: Laminated plates," Journal of Applied Mechanics, vol. 44, Trans. ASME, Vol. 99, Series E, pp. 669-676, December 1977.

[10] C. Y. K. Chee, L. Tong, and G. P. Steven, "A mixed model for composite plates with piezoelectric actuators and sensors," ACAM99, The Second Australian Congress on Applied Mechanics, pp. Paper R-011, Feb 1999.

[11] C. Y. K. Chee, L. Tong, and G. P. Steven, "A mixed model for adaptive composite plate with piezoelectric for anisotropic actuation," Computers \& Structures, vol. 77, pp. 253-268, 2000.

[12] N. J. Pagano and S. J. Hatfield, "Elastic Behavior of Multilayered Bidirectional Composites," AIAA Journal, vol. 10, pp. 931-933, 1972.

[13] A. K. Noor, "Free vibration of multi-layered composite plates," AIAA Journal, vol. 11, pp. 1038-1039, 1973.

[14] Y. W. Kwon and J. E. Akin, "Analysis of layered composite plates using a higherorder deformation theory," Computers \& Structures, vol. 27, No. 5, pp. 619-623, 1987.

[15] F.-G. Yuan and R. E. Miller, "A rectangular finite element for moderately thick flate plates," Computers \& Structures, vol. 30, pp. 1375-1387, 1988.

[16] Z. Jia-xiong and F. Ye-li, "A new higher-order theory to laminated plates and shells," Applied Mathematics and Mechanics, vol. 14 No. 1, pp. 23-28, Jan. 1990.

[17] A. K. Ghosh and S. S. Dey, "A Simple Finite Element for the Analysis of Laminated Plates," Computers \& Structures, vol. 44, pp. 585-596, 1992.

[18] A. K. Ghosh and S. S. Dey, "Free vibration of laminated composite plates- a simple finite element based on higher order theory," Computers \& Structures, vol. 52, pp. 397-404, 1994.

[19] N. D. Phan and J. N. Reddy, "Analysis of laminated composite plates using a higher order shear deformation theory," Int. J. Numer. Meth. Engng, vol. 21, pp. 2201-2219, 1985.

[20] P. K. Roy and N. Ganesan, "Studies on dynamic behaviour of a cantilever square plate with varying thickness," Computers \& Structures, vol. 47, No. 6, pp. 995-1003, 1993.

[21] S. Xiaoping and S. Liangxin, "An improved simple higher-order theory for laminated composite plates," Computers \& Structures, vol. 50, No. 2, pp. 231-236, 1994. 
[22] H. R. H. Kabir, "Analysis of a simply-supported plate with symmetric angle-ply laminations," Computers \& Structures, vol. 51, No. 3, pp. 299-307, 1994.

[23] G. Akhras and W. L. M. S. Cheung, "Finite strip analysis of anisotropic laminated composite plates using higher-order shear deformation theory," Computers \& Structures, vol. 52, No. 3, pp. 471-477, 1994.

[24] M. S. Qatu and A. Algothani, "Bending analysis of laminated plates and shells by different methods," Computers \& Structures, vol. 52, No. 3, pp. 529-539, 1994.

[25] S. A. V. E. Verijenko, and V. G. Piskunov, "Finite element based on shear and normal deformation theory for the analysis of laminated composite plates," Computers \& Structures, vol. 54, No. 5, pp. 789-807, 1995.

[26] J. Kong and Y. K. Cheung, "Three-dimensional finite element analysis of thick laminated plates," Computers \& Structures, vol. 57, No. 6, pp. 1051-1062, 1995.

[27] L. Jing-jing and C. Chang-jun, "Differential quadrature method for bending of orthotropic plates with finite deformation and transverse shear effects," Applied Mathematics and Mechanics, vol. 25, No. 8, pp. 878-884, Aug. 2004.

[28] M. C. Manna, "Free vibration analysis of isotropic rectangular plates using a highorder triangular finite element with shear," Journal of Sound and Vibration, vol. 281, pp. 235-259, 2005.

[29] A. A. Khdeir and J. N. Reddy, "An exact solution for the bending of thin and thick cross-ply laminated beams," Composite Structures, vol. 37, pp. 195-203, 1997.

[30] R. M. Jones, Mechanics of composite materials, second ed.: Taylor \& Francis, 1999.

[31] J. N. Reddy, "A Penalty Plate Bending Element for the Analysis of Laminated anisotropic Composite Plates," Int. J. Numer. Meth. Engng, vol. 15, pp. 1187-1206, 1980.

[32] S. C. Panda and R. Natarajan, "Finite element analysis of laminated composite plates," Int. J. Numer. Meth. Engng, vol. 14, pp. 69-79, 1979.

[33] A. S. Mawenya and J. D. Davies, "Finite element bending analysis of multilayer plates," Int. J. Numer. Meth. Engng, vol. 8, pp. 215-225, 1974.

[34] H. L. K. Moser and A. Schmid, "About the analysis of laminated composite structures, finite element in engineering applications," INTES GmgH, Stuttgart, pp. 395-416, 1987.

[35] D. R. J. Owen and Z. H. Li, "A refined analysis of laminated plates by finite element displacement method " Computers \& Structures, vol. 26, pp. 915-923, 1987.

[36] J. N. Reddy and A. A. Khdeir, "Buckling and vibration of laminated composite plates using various plate theories," AIAA Journal, vol. 27, p. 1808, 1989. 


\section{Appendix (A)}

The elements of the transformed symmetric stiffness matrix $[\bar{Q}]$ used in Eq.(7), are given by, [7, 30]:

$\bar{Q}_{11}=Q_{11} m^{4}+2\left(Q_{12}+2 Q_{66}\right) n^{2} m^{2}+Q_{22} n^{4}$

$\bar{Q}_{12}=Q_{12} m^{4}+\left(Q_{11}+Q_{22}-4 Q_{66}\right) n^{2} m^{2}+Q_{12} n^{4}$

$\overline{Q_{13}}=Q_{13} m^{2}+Q_{23} n^{2}$

$\overline{Q_{16}}=\left(Q_{11}-Q_{12}-2 Q_{66}\right) m^{3} n+\left(2 Q_{66}+Q_{12}+Q_{22}\right) m n^{3}$

$\bar{Q}_{22}=Q_{22} m^{4}+2\left(Q_{12}+2 Q_{66}\right) m^{2} n^{2}+Q_{11} n^{4}$

$\bar{Q}_{23}=Q_{23} m^{2}+Q_{13} n^{2}$

$\bar{Q}_{26}=\left(Q_{12}-Q_{22}+2 Q_{66}\right) m^{3} n+\left(Q_{11}-Q_{12}-2 Q_{66}\right) m n^{3}$

$\bar{Q}_{33}=Q_{33}$

$\bar{Q}_{36}=\left(Q_{13}-Q_{23}\right) m n$

$\bar{Q}_{66}=\left(Q_{11}+Q_{22}-2 Q_{12}-2 Q_{66}\right) m^{2} n^{2}+Q_{66}\left(m^{4}+n^{4}\right)$

$\bar{Q}_{44}=Q_{44} m^{2}+Q_{55} n^{2}$

$\bar{Q}_{45}=\left(Q_{55}-Q_{44}\right) m n$

$\bar{Q}_{55}=Q_{55} m^{2}+Q_{44} n^{2}$

$$
m=\cos (\theta), n=\sin (\theta)
$$

\section{Appendix (B)}

B-1- $\left[\bar{\varepsilon}^{0}(x, y)\right],\left[\bar{\varepsilon}^{1}(x, y)\right],\left[\bar{\varepsilon}^{2}(x, y)\right]$, and $\left[\bar{\varepsilon}^{3}(x, y)\right]$ used in Eq.(23):

$$
\left[\bar{\varepsilon}^{0}\right]=\left[\begin{array}{ccccccccccc}
\frac{\partial a_{1}^{T}}{\partial x} & 0 & 0 & 0 & 0 & 0 & 0 & 0 & 0 & 0 & 0 \\
0 & \frac{\partial a_{2}^{T}}{\partial y} & 0 & 0 & 0 & 0 & 0 & 0 & 0 & 0 & 0 \\
0 & 0 & 0 & 0 & 0 & a_{6}^{T} & 0 & 0 & 0 & 0 & 0 \\
0 & 0 & 0 & 0 & a_{5}^{T} & 0 & 0 & 0 & 0 & 0 & 0 \\
0 & 0 & 0 & a_{4}^{T} & 0 & 0 & 0 & 0 & 0 & 0 & 0 \\
\frac{\partial a_{1}^{T}}{\partial y} & \frac{\partial a_{2}^{T}}{\partial x} & 0 & 0 & 0 & 0 & 0 & 0 & 0 & 0 & 0
\end{array}\right]
$$




$$
\left[\bar{\varepsilon}^{1}\right]=\left[\begin{array}{ccccccccccc}
0 & 0 & -\frac{\partial^{2} a_{3}^{T}}{\partial x^{2}} & \frac{\partial a_{4}{ }^{T}}{\partial x} & 0 & 0 & 0 & 0 & 0 & 0 & 0 \\
0 & 0 & -\frac{\partial^{2} a_{3}^{T}}{\partial y^{2}} & 0 & \frac{\partial a_{5}{ }^{T}}{\partial y} & 0 & 0 & 0 & 0 & 0 & 0 \\
0 & 0 & 0 & 0 & 0 & 0 & 0 & 0 & 2 a_{9}^{T} & 0 & 0 \\
0 & 0 & 0 & 0 & 0 & \frac{\partial a_{6}^{T}}{\partial y} & 0 & 2 a_{8}^{T} & 0 & 0 & 0 \\
0 & 0 & 0 & 0 & 0 & \frac{\partial a_{6}^{T}}{\partial x} & 2 a_{7}^{T} & 0 & 0 & 0 & 0 \\
0 & 0 & -2 \frac{\partial^{2} a_{3}{ }^{T}}{\partial x \partial y} & \frac{\partial a_{4}{ }^{T}}{\partial y} & \frac{\partial a_{5}{ }^{T}}{\partial x} & 0 & 0 & 0 & 0 & 0 & 0
\end{array}\right]
$$

$$
\left[\bar{\varepsilon}^{2}\right]=\left[\begin{array}{ccccccccccc}
0 & 0 & 0 & 0 & 0 & 0 & \frac{\partial a_{7}^{T}}{\partial x} & 0 & 0 & 0 & 0 \\
0 & 0 & 0 & 0 & 0 & 0 & 0 & \frac{\partial a_{8}^{T}}{\partial y} & 0 & 0 & 0 \\
0 & 0 & 0 & 0 & 0 & 0 & 0 & 0 & 0 & 0 & 0 \\
0 & 0 & 0 & 0 & 0 & 0 & 0 & 0 & \frac{\partial a_{9}^{T}}{\partial y} & 0 & 3 a_{11}{ }^{T} \\
0 & 0 & 0 & 0 & 0 & 0 & 0 & 0 & \frac{\partial a_{9}^{T}}{\partial x} & 3 a_{10}{ }^{T} & 0 \\
0 & 0 & 0 & 0 & 0 & 0 & \frac{\partial a_{7}^{T}}{\partial y} & \frac{\partial a_{8}^{T}}{\partial x} & 0 & 0 & 0
\end{array}\right]
$$

$$
\left[\bar{\varepsilon}^{3}\right]=\left[\begin{array}{ccccccccccc}
0 & 0 & 0 & 0 & 0 & 0 & 0 & 0 & 0 & \frac{\partial a_{10}{ }^{T}}{\partial x} & 0 \\
0 & 0 & 0 & 0 & 0 & 0 & 0 & 0 & 0 & 0 & \frac{\partial a_{11}{ }^{T}}{\partial y} \\
0 & 0 & 0 & 0 & 0 & 0 & 0 & 0 & 0 & 0 & 0 \\
0 & 0 & 0 & 0 & 0 & 0 & 0 & 0 & 0 & 0 & 0 \\
0 & 0 & 0 & 0 & 0 & 0 & 0 & 0 & 0 & 0 & 0 \\
0 & 0 & 0 & 0 & 0 & 0 & 0 & 0 & 0 & \frac{\partial a_{10}{ }^{T}}{\partial y} & \frac{\partial a_{11}{ }^{T}}{\partial x}
\end{array}\right]
$$


B-2- $\left[\bar{U}^{0}(x, y)\right],\left[\bar{U}^{1}(x, y)\right],\left[\bar{U}^{2}(x, y)\right]$, and $\left[\bar{U}^{3}(x, y)\right]$ used in Eq.(30)

$$
\begin{aligned}
& {\left[\bar{U}^{0}\right]=\left[\begin{array}{ccccccccccc}
\left\{a_{1}\right\}^{T} & 0 & 0 & 0 & 0 & 0 & 0 & 0 & 0 & 0 & 0 \\
0 & \left\{a_{2}\right\}^{T} & 0 & 0 & 0 & 0 & 0 & 0 & 0 & 0 & 0 \\
0 & 0 & \left\{a_{3}\right\}^{T} & 0 & 0 & 0 & 0 & 0 & 0 & 0 & 0
\end{array}\right]} \\
& {\left[\bar{U}^{1}\right]=\left[\begin{array}{ccccccccccc}
0 & 0 & -\frac{\partial\left\{a_{3}\right\}^{T}}{\partial x} & \left\{a_{4}\right\}^{T} & 0 & 0 & 0 & 0 & 0 & 0 & 0 \\
0 & 0 & -\frac{\partial\left\{a_{3}\right\}^{T}}{\partial y} & 0 & \left\{a_{5}\right\}^{T} & 0 & 0 & 0 & 0 & 0 & 0 \\
0 & 0 & 0 & 0 & 0 & \left\{a_{6}\right\}^{T} & 0 & 0 & 0 & 0 & 0
\end{array}\right]} \\
& {\left[\bar{U}^{2}\right]=\left[\begin{array}{ccccccccccc}
0 & 0 & 0 & 0 & 0 & 0 & \left\{a_{7}\right\}^{T} & 0 & 0 & 0 & 0 \\
0 & 0 & 0 & 0 & 0 & 0 & 0 & \left\{a_{8}\right\}^{T} & 0 & 0 & 0 \\
0 & 0 & 0 & 0 & 0 & 0 & 0 & 0 & \left\{a_{9}\right\}^{T} & 0 & 0
\end{array}\right]} \\
& {\left[\bar{U}^{3}\right]=\left[\begin{array}{ccccccccccc}
0 & 0 & 0 & 0 & 0 & 0 & 0 & 0 & 0 & \left\{a_{10}\right\}^{T} & 0 \\
0 & 0 & 0 & 0 & 0 & 0 & 0 & 0 & 0 & 0 & \left\{a_{11}\right\}^{T} \\
0 & 0 & 0 & 0 & 0 & 0 & 0 & 0 & 0 & 0 & 0
\end{array}\right]}
\end{aligned}
$$




\section{Appendix (C)}

C-1- The used column vectors of the Ritz approximation functions for simply supported boundary conditions are:

$$
\begin{aligned}
& \left\{a_{1}(x, y)\right\}^{T}=\left[\left(y^{2}-b y\right)(2 x-a)\right] \\
& \left\{a_{2}(x, y)\right\}^{T}=\left[\left(x^{2}-a x\right)(2 y-b)\right] \\
& \left\{a_{3}(x, y)\right\}^{T}=\left[\begin{array}{llllll}
\bar{X} \bar{Y} & \bar{X}^{2} \bar{Y} & \bar{X} \bar{Y}^{2} & \bar{X}^{2} \bar{Y}^{2} & \bar{X}^{3} \bar{Y} & \bar{X} \bar{Y}^{3}
\end{array}\right] \\
& \left\{a_{4}(x, y)\right\}^{T}=\left[\left(1-\frac{6 x^{2}}{a^{2}}+\frac{4 x^{3}}{a^{3}}\right)\left(y-\frac{2 y^{3}}{b^{2}}+\frac{y^{4}}{b^{3}}\right)\right] \\
& \left\{a_{5}(x, y)\right\}^{T}=\left[\left(x-\frac{2 x^{3}}{a^{2}}+\frac{x^{4}}{a^{3}}\right)\left(1-\frac{6 y^{2}}{b^{2}}+\frac{4 y^{3}}{b^{3}}\right)\right] \\
& \left\{a_{6}(x, y)\right\}^{T}=\left[1\left(x-\frac{2 x^{3}}{a^{2}}+\frac{x^{4}}{a^{3}}\right)\left(y-\frac{2 y^{3}}{b^{2}}+\frac{y^{4}}{b^{3}}\right)\right] \\
& \left\{a_{7}(x, y)\right\}^{T}=\left[\left(y^{2}-b y\right)(2 x-a)\right] \\
& \left\{a_{8}(x, y)\right\}^{T}=\left[\left(x^{2}-a x\right)(2 y-b)\right] \\
& \left\{a_{9}(x, y)\right\}^{T}=\left[1\left(x-\frac{2 x^{3}}{a^{2}}+\frac{x^{4}}{a^{3}}\right)\left(y-\frac{2 y^{3}}{b^{2}}+\frac{y^{4}}{b^{3}}\right)\right] \\
& \left\{a_{10}(x, y)\right\}^{T}=\left[\left(1-\frac{6 x^{2}}{a^{2}}+\frac{4 x^{3}}{a^{3}}\right)\left(y-\frac{2 y^{3}}{b^{2}}+\frac{y^{4}}{b^{3}}\right)\right] \\
& \left\{a_{11}(x, y)\right\}^{T}=\left[\left(x-\frac{2 x^{3}}{a^{2}}+\frac{x^{4}}{a^{3}}\right)\left(1-\frac{6 y^{2}}{b^{2}}+\frac{4 y^{3}}{b^{3}}\right)\right]
\end{aligned}
$$


C-2- The used column vectors of the Ritz approximation functions for a cantilever plate are:

$$
\begin{aligned}
& \left\{a_{1}(x, y)\right\}^{T}=\left[\begin{array}{llll}
x & x y & x^{2} & x^{2} y
\end{array}\right]_{1 \times 4} \\
& \left\{a_{2}(x, y)\right\}^{T}=\left[\begin{array}{llll}
x^{2} & x^{2} y & x^{3} & x^{3} y
\end{array}\right]_{1 \times 4} \\
& \left\{a_{3}(x, y)\right\}^{T}=\left[\begin{array}{lllllllll}
x^{2} & x^{2} y & x^{3} & x^{2} y^{2} & x^{3} y & x^{4} & x^{3} y^{2} & x^{4} y & x^{4} y^{2}
\end{array}\right]_{1 x 9} \\
& \left\{a_{4}(x, y)\right\}^{T}=\left[\begin{array}{llll}
x & x y & x^{2} & x^{2} y
\end{array}\right]_{1 \times 4} \\
& \left\{a_{5}(x, y)\right\}^{T}=\left[\begin{array}{llll}
x & x y & x^{2} & x^{2} y
\end{array}\right]_{1 \times 4} \\
& \left\{a_{6}(x, y)\right\}^{T}=\left[\begin{array}{llll}
1 & x & y & x y
\end{array}\right]_{1 x 4} \\
& \left\{a_{7}(x, y)\right\}^{T}=\left[\begin{array}{llll}
x & x y & x^{2} & x^{2} y
\end{array}\right]_{1 \times 4} \\
& \left\{a_{8}(x, y)\right\}^{T}=\left[\begin{array}{llll}
x & x y & x^{2} & x^{2} y
\end{array}\right]_{1 \times 4} \\
& \left\{a_{9}(x, y)\right\}^{T}=\left[\begin{array}{llll}
1 & x & y & x y
\end{array}\right]_{1 x 4} \\
& \left\{a_{10}(x, y)\right\}^{T}=\left[\begin{array}{llll}
x & x y & x^{2} & x^{2} y
\end{array}\right]_{1 x 4} \\
& \left\{a_{11}(x, y)\right\}^{T}=\left[\begin{array}{llll}
x & x y & x^{2} & x^{2} y
\end{array}\right]_{1 x 4}
\end{aligned}
$$

